\title{
On the Allocation of Residues Cost using Conventional and Comprehensive Thermoeconomic Diagrams
}

\author{
P. R. Faria ${ }^{1,3, *}$, R. G. Santos ${ }^{2,3}$, J. J. C. S. Santos 3 , M. A. Barone ${ }^{3}$, B. M. F. Miotto ${ }^{3}$ \\ ${ }^{1}$ Federal Institute of Espírito Santo - IFES, Cariacica, Brazil \\ ${ }^{2}$ Federal Institute of Espírito Santo - IFES, Vitória, Brazil \\ ${ }^{3}$ Federal University of Espírito Santo - UFES, Vitória, Brazil \\ E-mail: 1pedro.faria@ifes.edu.br
}

Received 11 February 2021, Revised 11 March 2021, Accepted 12 April 2021

\begin{abstract}
In a productive process, the achievement of products occurs simultaneously with residues generation. Environmental impact of residues is an important issue in energy systems analysis due to environmental regulations and sustainability assessment. Many waste treatment methodologies have been proposed and applied in thermoeconomics. However, this is a complex problem and the solution depends on the residue nature and its formation process. Most conventional methodologies are based on productive diagrams, using productive flows only, and allocate the residues cost among the productive equipment. This work surveys the main conventional methodologies for treatment of waste and presents an improved/updated methodology based on a comprehensive diagram, in which both physical and productive flows are represented and their flows cost are assessed and the subsystems are connected using the same physical flows presented in the flowsheet of the plant. Both the CGAM system and a combined cycle are analyzed. Comparisons are made with literature results, considering the same case studies. The presented methodology obtains consistent results from the point of view of the cost allocation in thermoeconomics. The novelty of this updated approach concerns how the residue cost is allocated in the comprehensive diagram: it is reinternalized in the internal loop of physical flows, instead of in the productive unit. It represents advantages since the equipment product/fuel ratio index is not affected, which is beneficial for thermoeconomic diagnosis application.
\end{abstract}

\section{Keywords: Allocation of residue/waste; comprehensive diagram; cost allocation; P/F ratio; thermoeconomics.}

\section{Introduction}

In any productive process, the achievement of functional products occurs simultaneously with associated irreversibilities and often generating undesirable residue/waste [1]. Residues can be defined as flows that are not useful, and their existence would cause damage to the installation or to the environment. Therefore, additional energy consumption and economic resources are necessary in order to eliminate these flows and/or convert them into loss streams to be eliminated without losses or demanding more resources [2]. The words residue and waste are assumed to be synonymous in this work, for both heat in dissipative components and stack or chimney gases.

The dissipative equipment does not have a productive purpose, i.e., these components destroy exergy without thermodynamic gain. Nevertheless, they are essential for the correct system operation [3], [4]. Furthermore, this kind of equipment aims to eliminate totally/partially an undesirable flow (waste) through interactions with other components [1], which in some cases allows higher production or better efficiency for the system [1], [5]. According to [4], in costing applications, all costs associated with owning and operating a dissipative component must be charged directly to the component(s) served by it.

Concerns about the environmental impact of residues are gaining importance in the energy systems analyses as a result of environmental regulations and sustainability assessment that reinforces the importance of its adequate treatment. From a technical-economic as well as an environmental perspective, producing with maximum costeffectiveness is not enough, it also needs to consider how to minimize emissions of pollutants and waste disposals [1]. In this regard, the exergy is the most appropriate link between the second law and environmental issues, because it is a measure of the departure of the state of a system from that of the environment. In addition, the second law can provide instrumental insights into environmental problems [6], [7] and the exergy also provides the basis for developing comprehensive methodologies for sustainability as the confluence of energy, environment and sustainable development [6], [8].

Several works incorporate thermoeconomic models to calculate the environmental costs of the final products, such as specific $\mathrm{CO}_{2}$ emissions of each final product in thermal systems [9]-[20], to perform emissions allocation in Life Cycle Assessment (LCA) [21]-[27] and to carry out thermoeconomic optimization problems through environmental constraints equations and/or objective functions which take into account the emissions [28]-[32]. Meanwhile, the allocation of waste heat and residues costs are still open to criticism and it can be considered as an important challenge to be solved for the rational and 
systematic inclusion of equipment environmental costs and environmental taxes in thermoeconomics.

The existence of waste creates the need to determine its costs. Over the last years, many waste treatment methodologies have been proposed and applied. In the benchmark CGAM Problem [33], for instance, where four methodologies [34]-[37] were applied to a gas turbine cogeneration system, each one used a different thermoeconomic methodology and consequently treated waste (exhaust gases) differently. A few years later, the Exergetic Cost Theory (ECT) [34] was improved through its Structural Theory to treat waste more rationally [38] [40]. The Specific Exergy Costing (SPECO) [4] was proposed to try to generalize into a single methodology those that were proposed in the CGAM Problem.

In 2008, Torres and his co-workers proposed the mathematical basis for the cost assessment and the formation process of residues [1]. In their work, two residues cost allocation methodologies were applied and compared in a combined cycle with exhaust gases and condenser residual heat. Two other methodologies for allocating waste costs were proposed with the advising [41], in 2010, and participation [42] of Torres, in 2012, and both of them have used the same combined cycle as in [1] to compare the results.

The model proposed by Santos and co-workers [43], [44] already takes into account the dissipative component treatment and residues cost allocation automatically through its productive structure, which is defined based on the trajectories the flows describe in the h-s plane when they work for the specific purpose of the plant. In other words, it describes the behavior of thermodynamic cycles in the h-s plane taking into account the variation of enthalpy and entropy of the working fluid.

Nevertheless, residues cost allocation is a complex problem by reason of its dependence on the nature of such flows and how they have been formed [1], [41], [44]. In this regard, exergy disaggregation can be interesting to define the thermodynamic magnitude that better represents the system residue. In agreement with [45], the deeper and more detailed the disaggregation is, the clearer the interpretation of the obtained costs will be and the wider the catalog of applications to theoretical and practical problems.

According to Lozano and Valero [45] the ECT, as it was originally formulated, had limitations in defining the productive structure in relation to the same flows and components present in the physical structure. Thus, it creates difficulties in the adequate treatment of the dissipative components and residues of the plant. As the physical model is not enough to identify the waste formation process, the main methodologies utilize the productive diagram [1], [36], [37], [41], [42], [44] and agree that the cost of the exergy contained in the waste and the costs of the resources employed in its treatment or evacuation must be divided among the productive units, and thus to the final products, proportionally to its responsibility for such magnitude [45]. This proportionality can be defined in several different ways, i.e., there is no general criterion to define it. Hence, despite waste treatment is evolving and being widely discussed, it is still a thermoeconomic field open to improvement.

Bearing in mind the variety and quantity of thermoeconomic methodologies used for waste treatment and also the need to improve these analyzes, this work first surveys the main conventional available methodologies used in the treatment of waste and dissipative equipment, in order to identify and enumerate each the ones that will be compared. Then, an updated/improved methodology for residue cost allocation using the comprehensive diagram is presented. In the comprehensive diagram [46], [47], both physical and productive internal flows are represented and their flows cost are assessed. Besides, the subsystems are connected using the same physical flows presented in the flowsheet of the plant. It reduces possible arbitrariness related to the subsystem interconnections (as already shown in [47], [48]), since there are no fictitious components, such as junctions and branches used in productive diagrams.

The methodology presented in this paper, based on a comprehensive diagram, is applied in two case studies. The first is a combined cycle power plant with two kinds of residues (HRSG exhaust gases and condenser residual heat) in which the results are compared with the ones of five methodologies available in the literature [1], [41], [42], [44] that were applied in the same power cycle. The second is the CGAM Problem, a regenerative gas turbine cogeneration system, in which the HRSG exhaust gases are the residues. In this second case, the comprehensive diagram is first defined with total exergy flows (E Model) and then with exergy disaggregated in mechanical and thermal components $\left(\mathrm{E}^{\mathrm{T}} \& \mathrm{E}^{\mathrm{M}}\right.$ Model). The results are compared with the following methods available in the literature: some original methodologies [36], [37] applied in the CGAM Problem and others that had been improved later [4], [40], mainly for waste treatment, and also with the H\&S Model [43], [44].

The improved method of this paper agrees that the residues cost must be divided among the productive units, and thus to the final products, proportionally to its responsibility for such magnitude. Comparisons with the main methodologies used in this area are carried out. However, the main difference between this updated method, which was introduced in [49], and the conventional methods concerns how the residue cost allocation in the comprehensive diagram: in such case, it is reinternalized in the internal loop of physical flows, instead of in the productive unit, as in [1], [41], [42]. It represents a benefit during a future application of thermoeconomic diagnosis since it does not affect the equipment product/fuel ratio (unit exergy consumption), which is the performance index used in the thermoeconomic diagnosis method called "Fuel Impact Formula" [50], [51]. This method uses mathematical equations to determine the additional fuel consumption in the presence of system anomalies through thermodynamic data from the operational and reference conditions.

\section{Residue Cost Allocation Overview}

When the Exergetic Cost Theory (ECT) [34] was applied in the CGAM Problem [33], the waste cost was allocated to the Heat-Recovery Steam Generator (HRSG) only, and therefore its cost was charged only to the useful heat cost. The Exergoeconomic/AVCO [35], distributed the waste proportionally to the amount of power and heat produced. The two other methodologies applied in the CGAM Problem allocate waste implicitly proportionally to the thermal exergy consumption in the productive unit that produces the final products (Thermoeconomic Functional Approach - TFA [36]) and using negentropy flow consumption together with the thermal exergy component flow (Engineering Functional Analysis - EFA [37]). 
Whereas ECT and Exergoeconomic/AVCO have worked with physical diagrams, TFA and EFA have used productive diagrams. After the CGAM Problem, the same ECT authors developed a structural version of this theory as the standard thermoeconomic methodology whose mathematical formalism would be able of dealing with any of the other methodologies [38]-[40]. The Structural Theory of Exergetic Cost graphically represents the cost formation process through productive flows, called productive diagram.

Describing the cost formation process of thermal systems based on productive flows is originally a characteristic of functional methodologies, TFA and EFA. Nonetheless, this characteristic has also started to be adopted by the Structural ECT [52]. When this theory uses total exergy to define physical flows combined with the productive diagram, it is here called E Model. The Structural ECT and E Model allocate the residues implicitly and proportionally to the exergy consumption in the productive units that produce the final products of the plant.

The SPECO [4] indicates that costs associated with owning and operating a dissipative component must be charged directly to the component(s) it is served by and suggests that the waste, called exergy losses, should be charged directly to the combustion chamber. In this aspect, [4] agrees with [2], since the output gases of the HRSG has not been generated there, but in the combustion chamber, and that is where it should be allocated. Consequently, it was observed in [53], [54] that the unit costs of the final products are equal when the Structural ECT (Model E) and SPECO are applied to the CGAM Problem, which shows a possible unification between these methodologies when they use total exergy analysis. However, while the cost equations in the Structural Theory are used to calculate the unit cost of productive flows, in SPECO it is used to determine the unit cost of physical flows, originally.

The model proposed by Torres et al. [1] for analyzing the cost formation process of the residues is based on the symbolic exergoeconomic methodology [55]. In their work, two options of residues cost allocation are applied in a combined cycle: Option 1 allocates the cost of waste proportionally to the exergy of the flows processed in the dissipative units according to the productive structure of the plant, and Option 2 allocates it proportionally to the entropy generation along the process. The first defines the residue cost distribution ratio $\left(\psi_{j r}\right)$ based on how much exergy was produced in the equipment before being dissipated in the environment. In the second, the components which increase the entropy of working fluid are charged and those that reduce it receive a credit. The last one yields values greater than one and lesser than zero for the residue cost distribution ratio when applied to open systems, such as Brayton cycles. Thus, it is more suitable to be applied in closed cycles, like Rankine or Refrigeration cycles [56]. The $\psi_{j r}$ represents the fraction [\%] of the total cost of a waste that is allocated to a given component.

Two other methodologies for allocating waste costs [41], [42] are also based on the symbolic exergoeconomics and both used the same combined cycle as in [1] to compare the results. The criterion proposed in 2010 [41] is based on the entropy distributed within the components, instead of the entropy generated along the process, as it is in Option 2 [1]. The $\psi_{j r}$ values obtained by [41] are comprised between those obtained by Options 1 and 2 from [1]. Methodology [42] identifies the formation process of residues cost and allocates it to the productive units that generated them, in proportion to their respective responsibility. Methodologies [41] and [42] are identified here as Options 4 and 5, respectively. The criterion proposed by Agudelo et al. [42] has been applied in a retrofitted natural gas-based cogeneration system and to the original natural gas-based cogeneration system to achieve the unit exergoeconomic cost of products [57] and also in a CHP plant with three kinds of residues (exhaust gases, condenser residual heat and ashes) [20] that were treated by combining the residue cost allocation methodologies proposed in [1] and [42].

Whereas in the work of Torres et al. [1] the FuelProduct Matrix $\langle F P\rangle$ is composed by exergy flows to define the residue cost distribution ratios $\left(\psi_{j r}\right)$, Seyyedi et al. [41] use entropic exergy component flows in the Matrix $\langle F P\rangle$ for defining these ratios. These flows are defined from the exergy definition and can be written as $E_{i, j}^{S}=E_{i, j}^{H}-E_{i, j}$, in which $E_{i, j}$ is the total exergy variation between two physical states $\left(i\right.$ and $j$ ), $E_{i, j}^{S}$ and $E_{i, j}^{H}$ are, respectively, the variation of entropic and enthalpic components of exergy between $i$ and $j$ states.

Santos et al. [43], [44] proposed a general methodology, called H\&S Model (identified here as Option 3), which already takes into account the treatment of the dissipative components and the waste cost allocation in the thermoeconomic analysis of energy systems. In its productive structure, the fuels and the products of each component are systematically defined by taking into account all enthalpy, entropy and also chemical exergy additions to and removals from all the streams. The treatment of waste and dissipative equipment, which is already an inherent feature of this methodology, is carried out through the productive structure definition of the system, which is based on the trajectories the flows describe in the h-s plane when they work for the specific purpose of the plant. In other words, it describes the behavior of thermodynamic cycles in the h-s plane taking into account the variation of enthalpy and entropy of the working fluid. Moreover, it already treats waste and dissipative equipment without the need to define the $\psi_{j r}$. The H\&S Model was applied for residue cost allocation in a regenerative gas turbine cogeneration system [56], for treatment of dissipative components (condenser) and residues (exhaust gases) in a combined cycle [58] and in a Rankine cycle to treat the condenser [59]. Regarding residue cost allocation, there is a similarity between this last methodology and the one proposed by Seyyedi et al. [41], since both use the entropic component of exergy flows for residue allocation.

Since 2008, Torres et al. [1] mentioned that there is an evident needing for either developing new techniques or extending the existing ones for including both residues cost allocation and the analysis of their formation process. This same work concludes that despite advances in the area, this problem is still open because perhaps a subjective criterion is being used for cost allocation. Keshavarzian et al. [60], in 2017, also demonstrated the importance of the exergy cost reallocation of the residual flows in the thermoeconomic analysis in order to do not underestimate the exergy costs of useful products. Currently, several works are still working in this regard to improve analysis.

In [61] the ECT Method [34] and the Distributed Entropy Method [41] are applied to a high-temperature gascooled reactor that is coupled with the steam cycle through 
the heat exchanger. The results had been compared with the H\&S Model [44]. Seyyedi and Dogonchi [62] propose two new waste treatment alternatives based on combinations of already existing methodologies to overcome restrictions of the pre-existing ones. The authors had applied it to the same combined cycle used in [1], [41], [42]. The first alternative uses Option 2 [1] for the steam line (Rankine cycle) and Option 1 [1] is applied for air and gas lines (Brayton cycle). The second alternative suggests a combination of Options 1 and 2 to obtain a positive value between zero and one for the residue cost distribution ratios. Alternative 1 obtains the same $\psi_{j r}$ val ues, as in Opt ion 1, for gas es and approximated values for heat. Alternative 2 obtains analogous $\psi_{j r}$ val ues, as in Opt ion 2 , eve $\mathrm{n}$ wit $\mathrm{h}$ val ues greater than one and other negatives that had already been noticed in [1].

In the recent work [63], the authors applied and compared two methodologies - SPECO [4] and Modified Productive Structure Analysis (MOPSA) [64] - in a coalfired power plant and in the CGAM system. Both methodologies agree that the cost of waste eliminated at the dissipative units should be allocated to the system components. The MOPSA method includes the cost flow rate of irreversibility in the cost-balance equation (it acts as an input cost similar to the levelized cost of equipment, Z). On the other hand, SPECO provides waste costs elimination at dissipative units which are considered together with all components it serves. In [63] the authors conclude that if appropriate considerations about the waste cost (how and whether the waste cost term is explicit in the cost balance equation) in thermoeconomic analysis are taken into account, both methodologies obtain the same unit cost of products for both systems studied. The paper [63] was republicated as a book chapter in [65] with one more plant (a combined cycle), but with similar conclusions.

Lugo-Mendes et al. [66] use a residue cost criterion based on irreversibilities that can be conceived as an extension of the criterion of entropy changes (Option 2 [1]) because, in addition to the entropy changes, it also includes the exergy flows associated to the heat transfer through the boundaries of the energy system, and it is supported on the Gouy-Stodola theorem. Nevertheless, it avoids the existence of a negative production cost that usually happens in Option 2 and the residues costs are in direct proportion to the irreversibility or exergy destruction of the productive components. These production exergy costs are determined by allocating the residue cost formation to the irreversibilities of the productive components from which they originate. In [66] the authors apply the methodology in a Three-Pressure-Level Combined Cycle, and the results are compared with those obtained by Option 2 [1], Option 4 [41] and Option 5 [42]. Despite the proposed criterion reaching results in agreement with the compared criteria, it does not permit to calculate the costs of internal streams for assessing the impact of the additional fuel required to compensate component malfunctions. These same authors recently published an analysis of the waste cost formation of a high bypass turbofan engine used in aviation [67].

Finally, in 2021 Torres and Valero [68] revisited the ECT aiming to improve the analyses of the physical costs of products and their associated waste in energy systems.

The methodologies proposed by [1], [41], [42], [62], [66] as well as the one presented in this work are based on the $\psi_{j r}$ that are defined by different criteria. Non etheless, the biggest contribution of this work is due to the kind of diagram used and the difference concerning the residue costs reinternalization with advantage in a future application of thermoeconomic diagnosis. It will be further explained in subsections 4.1.2 and 4.2.2.

\section{Thermoeconomic Modeling}

A thermoeconomic model must be used in order to determine the exergetic and monetary unit costs of the external resource allocation to the final products and, consequently, for the assessment of the exergetic and the monetary unit cost of both internal flows and final products. This model can be defined as a set of cost equations that describes mathematically the cost formation process of the system's final products. A thermoeconomic model is usually performed by using Eqs. (1) and (2). All thermoeconomic methodologies agree that the productive purpose of the subsystems need to be defined, as well as the distribution of the external resources throughout the system, which can be represented by means of a diagram as shown in Figures 1-10.

Regardless of whether a physical (Figures 1 and 5) or productive (Figures 2-3 and 6-8) diagram is used as the thermoeconomic model, the solution of the set of cost Eq. (1) is the monetary unit cost of each internal flow and each final product which is the amount of external monetary unit required to obtain one unit of this flow, i.e., it is a measure of the economic efficiency of the production process when producing this flow [69]

$\sum\left(c_{\text {out }} \cdot Y_{\text {out }}\right)-\sum\left(c_{\text {in }} \cdot Y_{\text {in }}\right)=c_{F} \cdot E_{F}+Z$

$Z$ represents the external hourly cost of the subsystem due to the capital cost, operation and maintenance cost of each subsystem (in $\$ / \mathrm{h}$ ); $c_{F}$ is a known market unit cost of the external fuel exergy (in $\$ / \mathrm{kWh}$ ) and $E_{F}$ is the amount of the plant external fuel exergy consumption (in $\mathrm{kW}$ ). $c_{\text {out }}$ and $c_{i n}$ are unknown variables representing the monetary unit cost of the internal flows at the outlet and at the inlet of each subsystem (in $\$ / \mathrm{kWh}$ ), respectively. $Y_{\text {out }}$ and $Y_{\text {in }}$ represent the generic internal flows (in $\mathrm{kW}$ ) at the outlet and at the inlet of each subsystem, respectively, which can be assessed using any thermodynamic magnitude, such as, power $(\mathrm{P})$, heat $(\mathrm{Q})$, total exergy $(\mathrm{E})$, entropic $(\mathrm{S})$, enthalpic $(\mathrm{H})$, thermal $\left(\mathrm{E}^{\mathrm{T}}\right)$ and mechanical $\left(\mathrm{E}^{\mathrm{M}}\right)$ components, etc.

In order to formulate the cost equation balances to provide the exergetic unit cost ( $k_{\text {out }}$ and $k_{\text {in }}$ ) of each internal flow and final products of the diagram, Eq. (2) is obtained by modifying Eq. (1). The exergetic unit cost of a flow (in $\mathrm{kW} / \mathrm{kW}$ ) is the amount of exergy required to obtain one exergy unit of this flow and it is a measure of the thermodynamic efficiency of the production process generating this flow [69]. In Eq. (2), the hourly cost of the subsystem due to the capital cost, operation and maintenance must be zero $(Z=0)$ and the monetary unit cost of the external fuel exergy is replaced by the exergetic unit cost of the external fuel exergy, which is $1 \mathrm{~kW} / \mathrm{kW}$, because there is no exergy destruction before the productive process is performed [69].

$\sum\left(k_{\text {out }} \cdot Y_{\text {out }}\right)-\sum\left(k_{\text {in }} \cdot Y_{\text {in }}\right)=k_{F} \cdot E_{F}$

In the comprehensive diagrams (Figures 4, 9 and 10), in turn, the set of Eqs. (1) and (2) needs to be applied in all the productive units and components. Meanwhile, for both 
monetary and exergetic unit costs, the number of internal flows is always greater than the number of productive units and components. Therefore, auxiliary equations are required and both of them use the fuel and product principles [4] which is in accordance with the propositions formulated in the ECT [34], [70] for determining costs. In this work, only the exergetic unit cost is assessed and compared.

All the methodologies compared in this work, and which use the productive diagram, use the product principle, except the EFA [37] which uses the concept of by-product in defining the cost of some flows (it will be further explained and applied in subsection 4.2.1).

\section{Case Studies}

In order to be compared with several methodologies explained in section 2, the improved methodology of this paper is applied in two case studies: (i) a combined cycle power plant with two kinds of residues and (ii) in the CGAM system (only one kind of residue).

\subsection{Combined Cycle Power Plant}

Figure 1 shows the physical structure and Table 1 represents the thermodynamic parameters of the combined cycle which is used to compare the methodology of this work with Options 1-5 [1], [41], [42], [44]. Part of the power generated in the gas turbine (equipment $n^{\circ} 3$ ) is used to drive the compressor (equipment $n^{\circ} 2$ ) and part of the mechanical power drives the pump (equipment $n^{\circ} 8$ ). The final product of the plant (electric power) is represented by flow number 18 and the residues by flows 19 and 21 , condenser residual heat and exhausts gases, respectively. This cycle is fully described in [71].

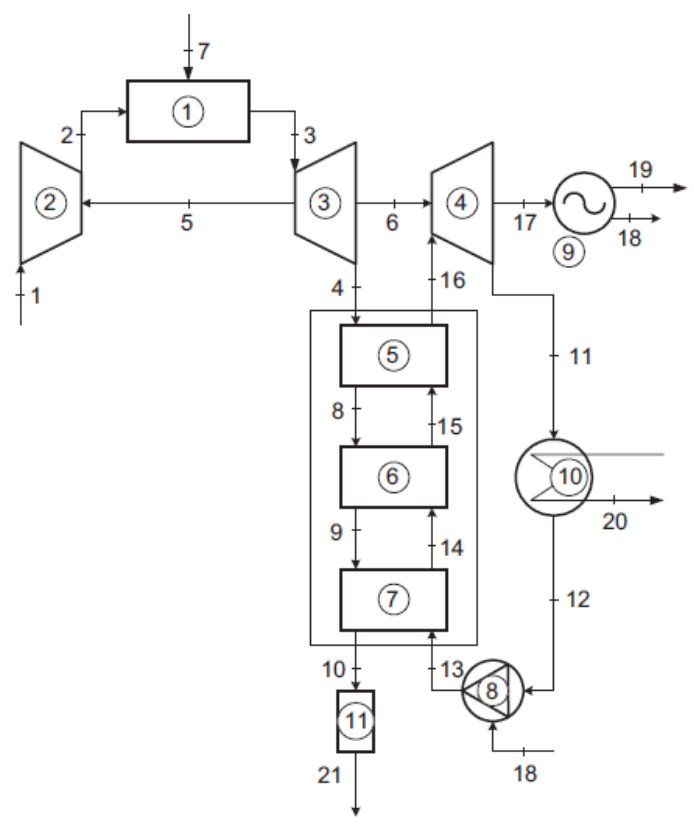

Figure 1. Physical structure of the combined cycle [41].

\subsubsection{Conventional Thermoeconomic Diagrams}

Some methodologies compared in this work use the total exergy (E) as the thermodynamic magnitude to define the productive structure. Table 2 represents the productive structure definition and Figure 2 shows the productive diagram of the plant using total exergy flows as used in the methodologies [1], [41], [42] and its respectively Options 1, 2, 4 and 5. In Figure 2 all the flows of the productive diagram are exergies that represent power, useful heat exergy, or the exergy of the working fluid $\left(E_{i: j}\right)$ that are exergy variations between two physical states: $E_{i: j}=E_{i}-$ $E_{j}$. In this kind of method, if the working fluid exergy variation when passing through an equipment is positive, it is classified as a product. Otherwise, fuel.

Table 1. Thermodynamic parameters of the combined cycle [1].

\begin{tabular}{clccc}
\hline $\mathbf{N}^{\mathbf{o}}$ & Flow Description & $\mathbf{P}(\mathbf{b a r})$ & $\mathbf{T}\left({ }^{\circ} \mathbf{C}\right)$ & $\mathbf{m} \mathbf{( k g / s )}$ \\
\hline 0 & Environment & 1.013 & 20.00 & \\
1 & Air inlet compressor & 1.013 & 331.23 & 309.930 \\
2 & Air outlet compressor & 9.100 & 870.00 & 309.930 \\
3 & Gas inlet turbine & 9.009 & 870.00 & 314.055 \\
4 & Gas inlet superheater & 1.044 & 444.17 & 314.055 \\
5 & Power compressor & & & \\
6 & Power gas turbine & & & \\
7 & Fuel combustor & 1.013 & 25.00 & 4.125 \\
8 & Gas inlet boiler & 1.033 & 406.09 & 314.055 \\
9 & Gas inlet economizer & 1.023 & 262.22 & 314.055 \\
10 & Gas outlet economizer & 1.013 & 184.20 & 314.055 \\
11 & Outlet LP turbine & 0.065 & 37.64 & 30.904 \\
12 & Outlet condenser & 0.065 & 37.67 & 30.904 \\
13 & Steam inlet economizer & 40.804 & 37.91 & 30.904 \\
14 & Steam inlet boiler & 40.400 & 251.00 & 30.904 \\
15 & Steam inlet superheater & 40.400 & 251.00 & 30.904 \\
16 & Steam inlet HP turbine & 40.000 & 417.13 & 30.904 \\
17 & Power steam turbine & & & \\
18 & Electric power & & & \\
19 & Condenser heat & & & \\
20 & Power extraction pump & & & \\
\hline & & & & \\
\hline
\end{tabular}

Table 2. The productive structure definition of the combined cycle.

\begin{tabular}{clcccc}
\hline $\mathbf{N}^{\mathbf{0}}$ & \multicolumn{1}{c}{ Device } & Fuel & Product & Residue & $\begin{array}{c}\text { Type of } \\
\text { component }\end{array}$ \\
\hline 1 & Combustor & $\mathrm{E}_{7}$ & $\mathrm{E}_{3}-\mathrm{E}_{2}$ & - & Productive \\
2 & Compressor & $\mathrm{E}_{5}$ & $\mathrm{E}_{2}-\mathrm{E}_{1}$ & - & Productive \\
3 & Gas Turbine & $\mathrm{E}_{3}-\mathrm{E}_{4}$ & $\mathrm{E}_{5}+\mathrm{E}_{6}$ & - & Productive \\
4 & LP Turbine & $\mathrm{E}_{16}-\mathrm{E}_{11}$ & $\mathrm{E}_{17}$ & - & Productive \\
5 & Superheater & $\mathrm{E}_{4}-\mathrm{E}_{8}$ & $\mathrm{E}_{16}-\mathrm{E}_{15}$ & - & Productive \\
6 & Boiler & $\mathrm{E}_{8}-\mathrm{E}_{9}$ & $\mathrm{E}_{15}-\mathrm{E}_{14}$ & - & Productive \\
7 & Economizer & $\mathrm{E}_{9}-\mathrm{E}_{10}$ & $\mathrm{E}_{14}-\mathrm{E}_{13}$ & - & Productive \\
8 & Pump & $\mathrm{E}_{20}$ & $\mathrm{E}_{13}-\mathrm{E}_{12}$ & - & Productive \\
9 & Generator & $\mathrm{E}_{6}+\mathrm{E}_{17}$ & $\mathrm{E}_{18}+\mathrm{E}_{20}$ & - & Productive \\
10 & Condenser & $\mathrm{E}_{11}-\mathrm{E}_{12}$ & - & $\mathrm{E}_{19}$ & Dissipative \\
11 & Stack & $\mathrm{E}_{10}$ & - & $\mathrm{E}_{21}$ & Dissipative \\
\hline
\end{tabular}

Figure 3 represents the productive diagram for the combined cycle using H\&S Model (Option 3) [43], [44] in which the flows are defined using the variation of the enthalpic $\left(H_{i: j}\right)$ and entropic $\left(S_{i: j}\right)$ components of the exergy between the physical states $i$ and $j$, respectively. H\&S Model gives credit to processes that decrease the entropy of the working fluid, and penalizes those processes that increase the entropy of the working fluid and it is based on exergy disaggregation. Besides, in this model, the chemical exergy flow $\left(\mathrm{CH}_{3: 2}\right.$ in Figure 3$)$ is explicitly introduced in the productive diagram.

The entropic component is produced in the condenser (equipment $\mathrm{n}^{\mathrm{o}}$. 10) and distributed directly to the Rankine Cycle, equipment 4-8 through the bifurcation $\mathrm{B}_{2}{ }_{2}$. Furthermore, after going through 5, 6, 7 and joining it with stack $\left(\mathrm{n}^{\circ} .11\right)$ product, it is indirectly distributed (through 
$\mathrm{B}^{\mathrm{S}}$ ) to the gas turbine cycle, equipment 1-3. In the H\&S Model, the equipment $n^{\circ} .11$ can be understood as the stack together with the environment.

In Figure 3, the systems' components are represented by means of rectangles that are real units or subsystems and the rhombus and circles are fictitious units called junctions (J) and bifurcations (B), respectively.

In this method, the fuel and product definitions of the enthalpic component and the chemical exergy (positive terms as shown in the exergy definition in its components in Eq. (3)) are performed similarly to the E Model. For the entropic component, the behavior is the opposite. As this component has a negative contribution in Eq. (3), if there is an increase in entropy variation, this will be fuel, otherwise, product.

$$
E_{i: j}=H_{i: j}-S_{i: j}+E_{i: j}^{C H}
$$

All other methodologies [1], [41], [42] which use productive diagram, except the H\&S Model, firstly consider the waste as if it were a final product of the plant and after its costs are redistributed/reallocated to the productive equipment through the residue cost distribution ratios $\left(\psi_{j r}\right)$. The methodologies differ from each other, mainly, by the $\psi_{j r}$ values.

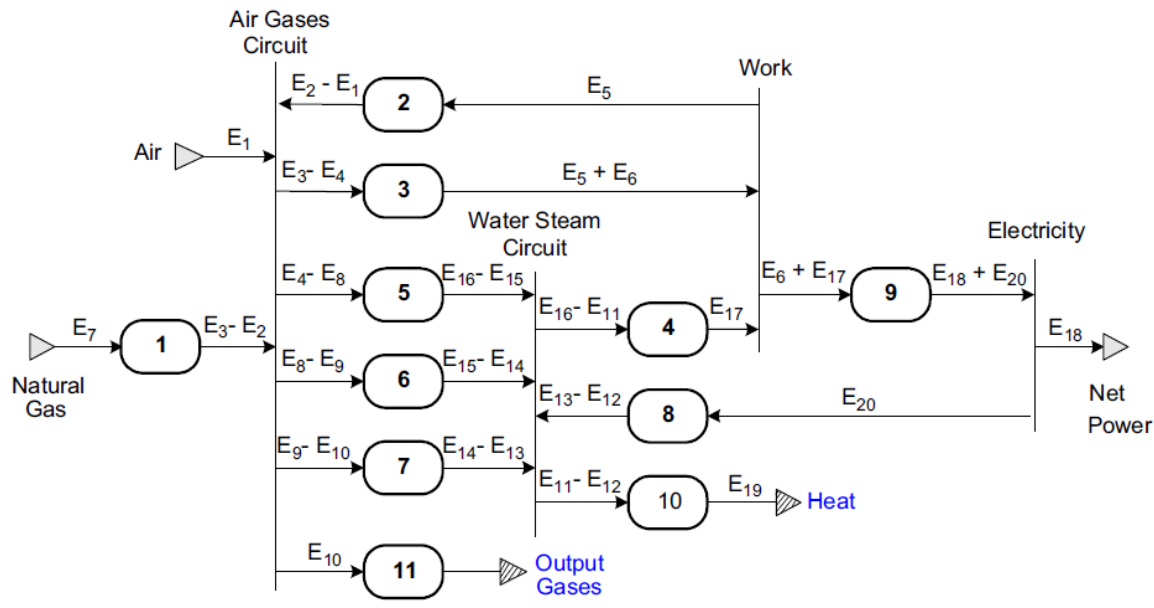

Figure 2. Productive diagram for the combined cycle using total exergy flows [1], [41].

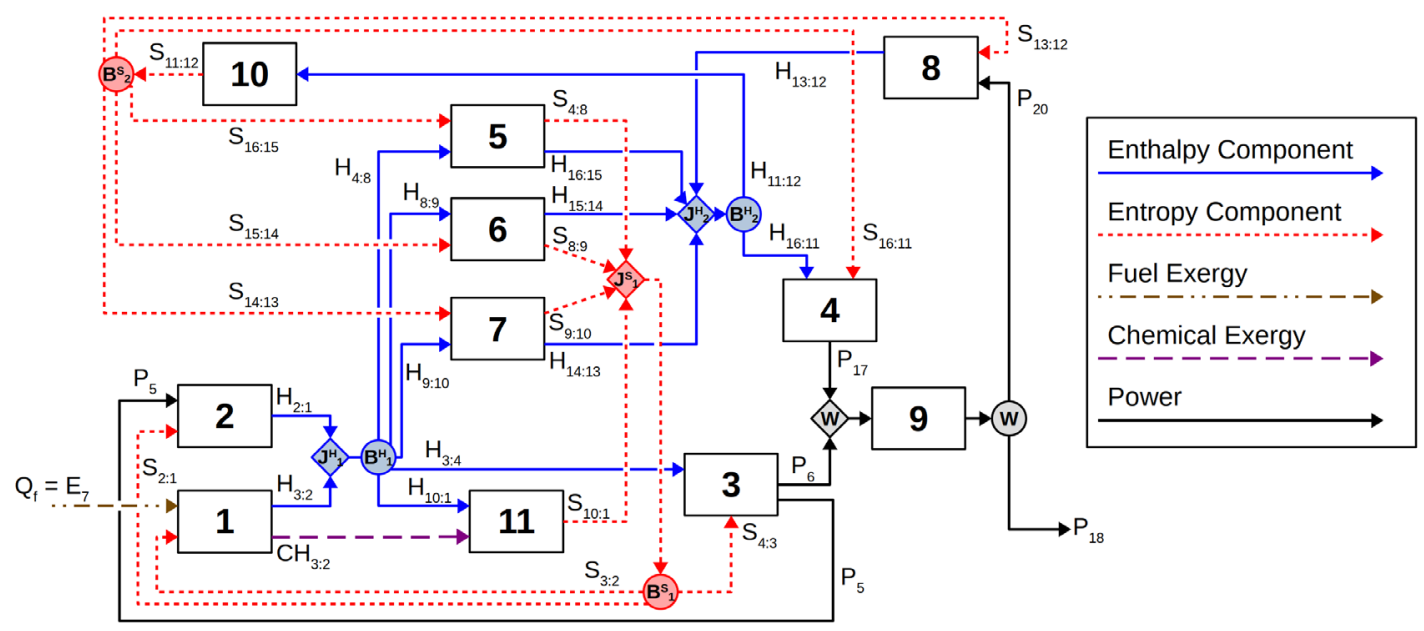

Figure 3. Productive diagram of the combined cycle (H\&S Model).

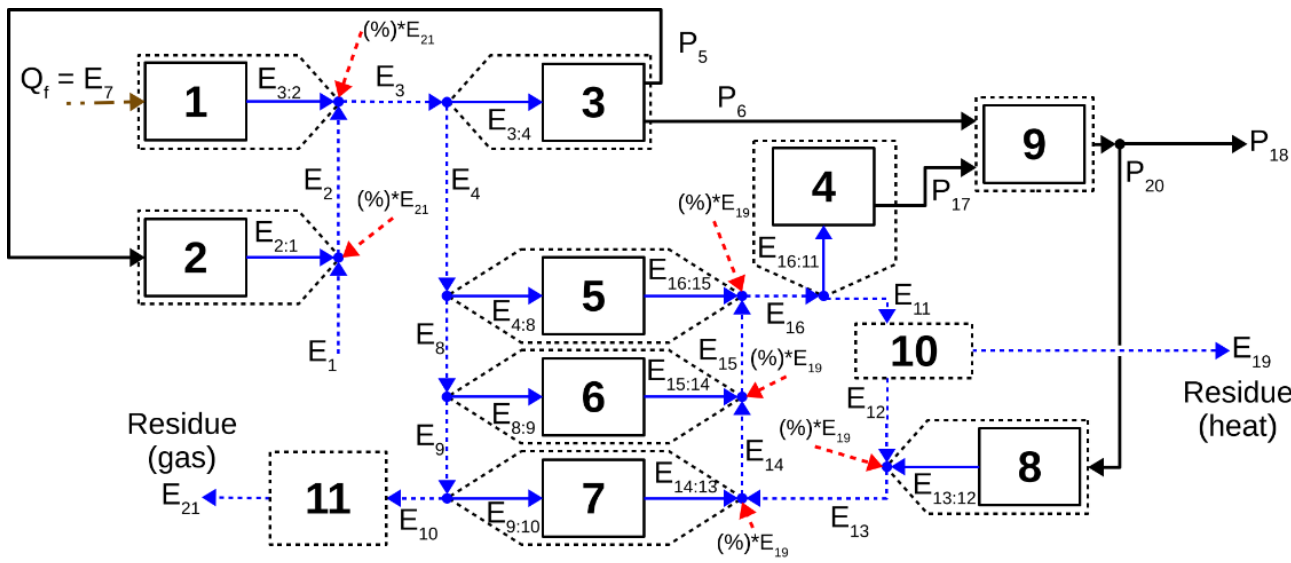

Figure 4. Comprehensive diagram for the combined cycle (E Model). 


\subsubsection{Comprehensive Thermoeconomic Diagrams}

Figure 4 combines the concept of both physical and productive diagram in a comprehensive thermoeconomic diagram representing the combined cycle and shows clearly and graphically the product and fuel of the subsystems, as well as the interrelation among them, by combining physical $\left(E_{i}\right)$ and productive $\left(E_{i: j}\right)$ internal flows in a single diagram. It also reduces arbitrariness linked to the junction-bifurcations used in productive diagrams. In comprehensive diagrams, each subsystem acts as both a productive unit (continuous line) and as a component (dotted line) combining the characteristics of both the productive and physical diagrams, respectively. The product and fuel definitions in the diagram are similar to those explained for the productive diagram (E Model).

Even though Frangopoulos [72] had mentioned and represented a new approach for constructing a thermoeconomic diagram encompassing both flows, the author did not present the cost equation for this approach. Lazzaretto and Tsatsaronis [4] also had discussed the concepts of productive unit and component, but they did not use the concept of productive unit for unit cost calculation. Von Spakovsky [37] had used the concept of internal loop flows, but in an optimization problem.

This kind of diagram, which combines physical and productive flows, has also been used in diagnosis analysis [73]-[75]. Nevertheless, for cost allocation applications, it was first done in 2018: while in [46], [47] the authors called by Comprehensive Diagram, in [76], [77] an equivalent diagram is called by Productive Structure Graph and the internal loops are called productive groups or streams.

In the methodology used here, which uses the comprehensive diagram, the residues costs are allocated in the component that has generated them. In Figure 4 the diagram is defined with exergy flows, therefore the exhaust gas $\left(E_{21}\right)$ costs should be reallocated where this magnitude (exergy) was produced: combustor and compressor, equipment 1 and 2, respectively. Nonetheless, it is necessary to carry out the reallocation proportionally to penalize equipment properly. Hence, the residues are allocated as shown by the red arrows entering components 1 and 2 in Figure 4 and the proportionality (\%), called by residue cost distribution ratios $\left(\psi_{j r}\right)$, are shown in Table 5: $60,69 \%$ to the combustor and $39,31 \%$ to the compressor.

The condenser residual heat $\left(\mathrm{E}_{19}\right)$ cost must be reallocated in a similar way (exergy internal loop), where it was produced (components 5-8, in Figure 4) using $\psi_{j r}$ shown in Table 5 (heat column).

\subsection{Regenerative Gas Turbine Cogeneration System}

Figure 5 represents the regenerative gas turbine cogeneration system that is the same as the well-known CGAM Problem in its optimal conditions [33]. The cogeneration system is defined by the AC (air compressor), the $\mathrm{R}$ (regenerator), the $\mathrm{CC}$ (combustion chamber), the GT (gas turbine) and the RB (recovery boiler). The parameters of the main flows of the physical structure are given in Table 3. The cogeneration plant delivers $30 \mathrm{MW}$ of net power $\left(\mathrm{P}_{\mathrm{N}}\right)$ and the power to drive the compressor $\left(\mathrm{P}_{\mathrm{AC}}\right)$ is $29,692.5 \mathrm{~kW}$. The fuel consumption in the exergetic base $\left(\mathrm{Q}_{\mathrm{F}}\right)$ is $84,380.69 \mathrm{~kW}$ and the useful heat exergy $\left(\mathrm{Q}_{\mathrm{U}}\right)$ produced by the recovery boiler is $12,740 \mathrm{~kW}$.

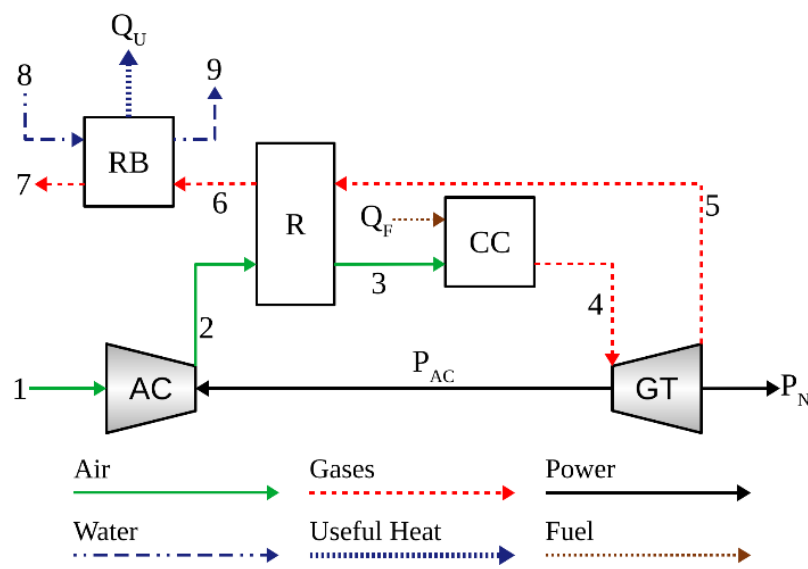

Figure 5. Physical structure of the CGAM system.

Table 3. Main parameters of the CGAM system.

\begin{tabular}{ccccc}
\hline \multicolumn{2}{c}{$\begin{array}{c}\text { Physical flow } \\
\text { Description }\end{array}$} & $\dot{\boldsymbol{m}[\mathbf{k g} / \mathbf{s}]}$ & $\mathbf{T}\left[{ }^{\circ} \mathbf{C}\right]$ & $\mathbf{p ~ [ k P a ]}$ \\
\hline 1 & Air & 99.46 & 25.15 & 101.3 \\
2 & Air & 99.46 & 322.51 & 863.4 \\
3 & Air & 99.46 & 641.28 & 820.2 \\
4 & Gas & 101.08 & $1,219.63$ & 779.2 \\
5 & Gas & 101.08 & 714.90 & 109.9 \\
6 & Gas & 101.08 & 445.76 & 106.6 \\
7 & Gas & 101.08 & 127.26 & 101.3 \\
\hline
\end{tabular}

\subsubsection{Conventional Thermoeconomic Diagrams}

The productive diagrams of the system according to TFA [36] and EFA [37] are shown in Figures 6(a) and 6(b), respectively. The TFA uses flows of exergy disaggregated in their thermal and mechanical components to define the productive structure and the residues are allocated implicitly to final products $\left(\mathrm{P}_{\mathrm{N}}\right.$ and $\left.\mathrm{QU}_{\mathrm{U}}\right)$ proportionally to the fuels of the GT and the RB, respectively. The EFA uses exergy flows, disaggregated in their thermal and mechanical components, joined up with the negentropy flows. In this specific case, residues are allocated through the environment $(\mathrm{E})$, originally called stack in this method. The thermal component of the exhaust gases $-E^{\mathrm{T}} 7: 1$ (or residues) is delivered to the environment and afterward, it is redistributed to the productive units proportionally to the increase of entropy in the working fluid (partial or total) caused by these productive units.

The methodologies TFA and EFA did not need to use a cost allocation rule since they were initially used in an optimization problem (CGAM). However, subsequent works showed that the TFA uses the product principle for cost allocation procedures [3], [38], [78]. On the other side, the EFA uses the by-product criterion to define auxiliary equations. This criterion considers that each plant can have only one product [52], [79]. Thus, in this case, as they are by-products, the negentropy flows produced by the RB $\left(\mathrm{S}_{6: 7}\right)$ and by the $\mathrm{R}\left(\mathrm{S}_{5: 6}\right)$ assume the same unit cost as the negentropy flow produced by the $E\left(S_{7: 1}\right)$, which is the unit whose main objective is to produce this flow.

In Figure 7 the productive diagram is defined using exergy flows as a characteristic of the Structural ECT (E Model) and the residues costs are allocated, implicitly, to the final products $\left(\mathrm{P}_{\mathrm{N}}\right.$ and $\left.\mathrm{Q}_{\mathrm{U}}\right)$ in proportion to the exergetic fuels of the GT and the RB, respectively. 


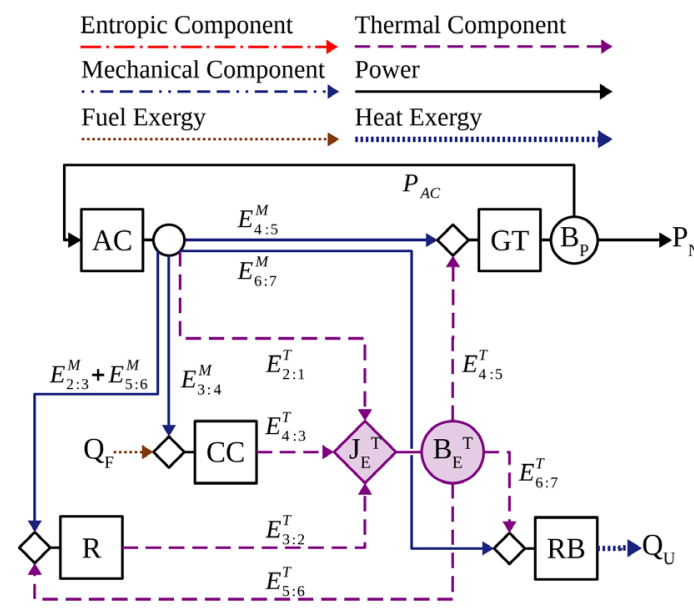

(a)

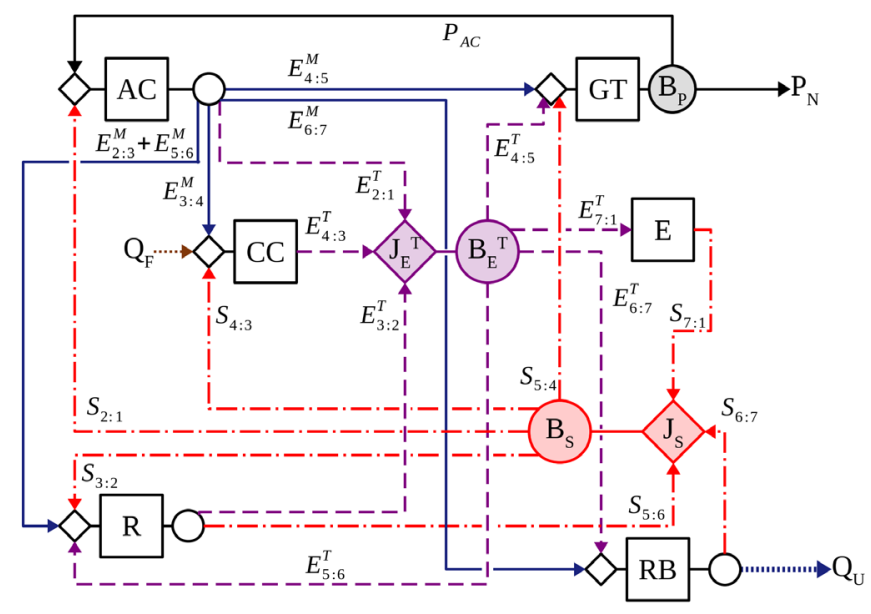

(b)

Figure 6. Productive diagram of the CGAM system according to a) TFA and b) EFA.

Figure 8 represents the productive diagram for the regenerative cogeneration cycle using H\&S Model [43], [44] in which the dissipative component is the environment (E), where the residues are dissipated. The chemical exergy flow $\left(\mathrm{CH}_{4: 3}\right.$ in Figure 8$)$ is explicitly in the productive diagram. Two residues' components are generated in the system: the chemical (originated in the combustion chamber) and the enthalpic. Both of them are dissipated or reduced in the environment to reduce the working fluid entropy from gases to the air states. The $\mathrm{CH}_{4: 3}$ value is $1,404.58 \mathrm{~kW}$.

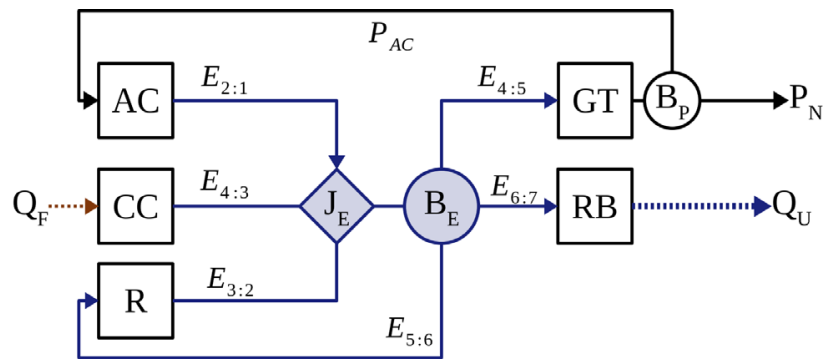

Figure 7. Productive diagram of the CGAM system (E Model).

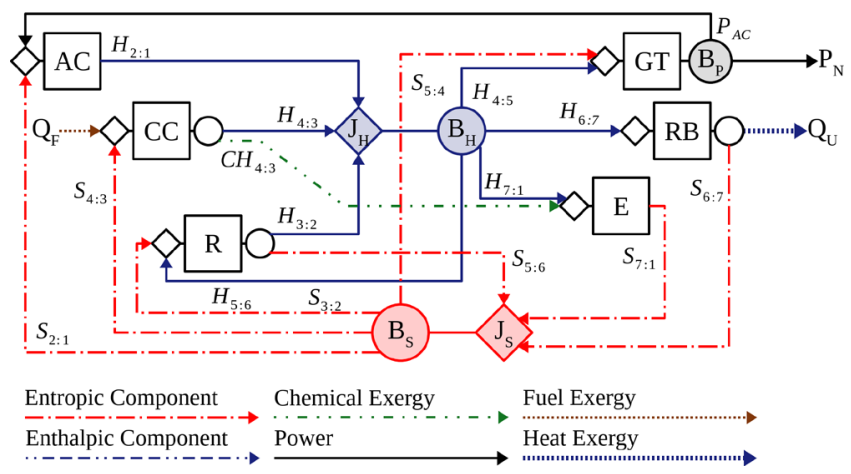

Figure 8. Productive diagram of the CGAM system (H\&S Model).

\subsubsection{Comprehensive Thermoeconomic Diagrams}

Figure 9 shows the comprehensive diagram of the regenerative cogeneration system in which the flows are defined by exergy without disaggregation, called E Model (Total Exergy). The residue is represented by total exergy flow $E_{7: 1}$. According to the proposal of this work for the residue treatment, its costs must be reallocated to the components in which they were generated, i.e., where there was an increase in the working fluid exergy. Hence, it is reallocated in the $\mathrm{AC}, \mathrm{R}$ and $\mathrm{CC}$ as shown by the red arrows entering these components in Figure 9. The proportionalities of the exergy increase in each component, which is represented by the $\psi_{j r}$, are shown in Table 6 .

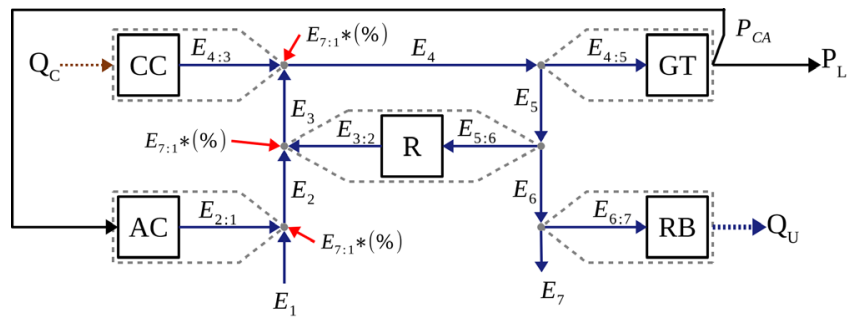

Figure 9. Comprehensive diagram of the CGAM system (E Model).

Figure 10 shows the comprehensive diagram of the CGAM system in which the flows are defined by exergy thermal and mechanical components - Model $\mathrm{E}^{\mathrm{T}} \& \mathrm{E}^{\mathrm{M}}$. There are two internal loops, one for each component, which are represented by different colors: blue and purple for the mechanical and thermal components, respectively. Since both components have a positive contribution in the exergy definition shown in Eq. (4), the product and fuel definitions in the diagram are similar to those explained for the productive diagram with E Model.

$E_{i: j}=E_{i: j}^{T}+E_{i: j}^{M}$

The residues are considered only by the thermal exergy component $\left(\mathrm{E}^{\mathrm{T}} \mathrm{7:1}\right)$ since the exhaust gases leave at ambient pressure and therefore there are no residues of the mechanical exergy component. The red arrows, in Figure 10, show where the residues costs are reallocated taking into account where it was produced and the proportion (Table 6) generated in each component. In both comprehensive diagrams, Figures 9 and 10, each subsystem acts as both a productive unit (continuous line) and as a component (dotted line).

\section{Results and discussion}

The results of the two case studies presented in subsections 4.1 and 4.2 are shown below in subsections 5.1 and 5.2, respectively. 


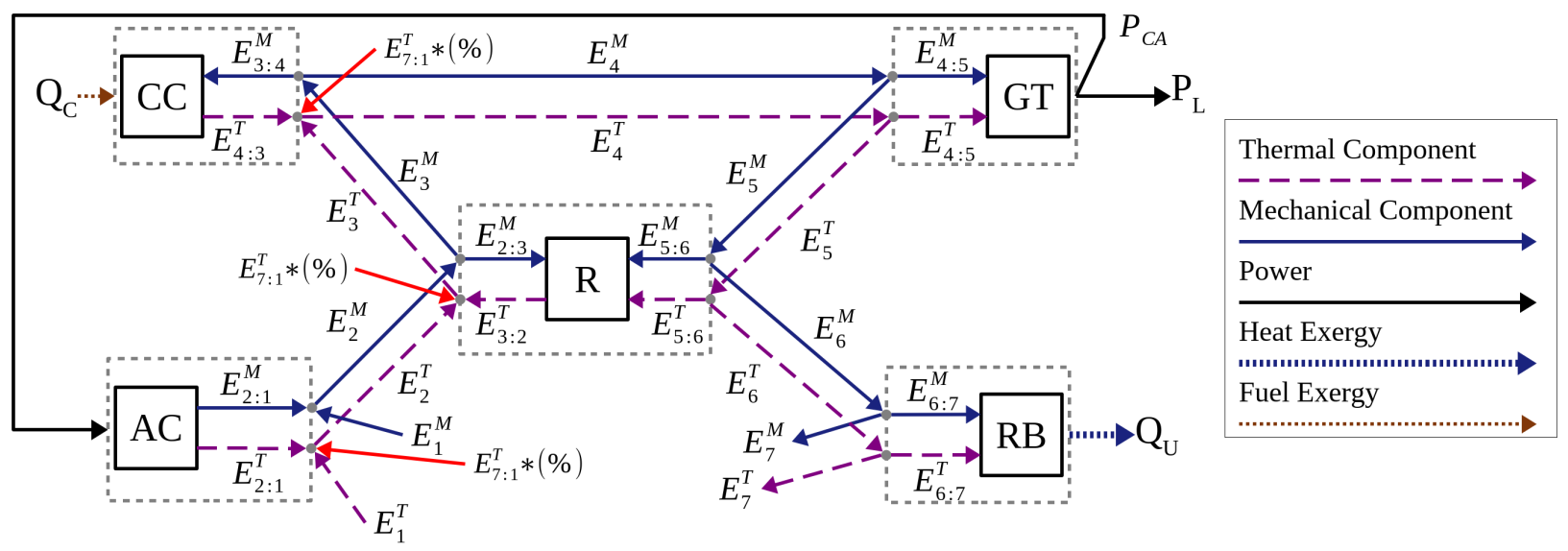

Figure 10. Comprehensive diagram of the CGAM system (Model $E^{T} \& E^{M}$ ).

Table 4. Residue cost distribution ratios, $\psi_{j r}[\%]$.

\begin{tabular}{|c|c|c|c|c|c|c|c|c|c|}
\hline \multirow{2}{*}{$\mathbf{N}^{\circ}$} & \multirow{2}{*}{ Device } & \multicolumn{2}{|c|}{ Option 1} & \multicolumn{2}{|c|}{ Option 2} & \multicolumn{2}{|c|}{ Option 4} & \multicolumn{2}{|c|}{ Option 5} \\
\hline & & Heat & Gases & Heat & Gases & Heat & Gases & Heat & Gases \\
\hline 1 & Combustor & - & 0.6069 & - & 1.71270 & - & 0.7160 & 0.381480 & 0.724598 \\
\hline 2 & Compressor & - & 0.3931 & - & 0.15770 & - & 0.2840 & 0.032791 & 0.255046 \\
\hline 3 & Gas Turbine & - & - & - & 0.15860 & - & - & 0.020416 & 0.020356 \\
\hline 4 & LP Turbine & - & - & 0.0553 & - & - & - & 0.000069 & - \\
\hline 5 & Superheater & 0.1832 & - & 0.1147 & -0.12120 & 0.1440 & - & 0.098189 & - \\
\hline 6 & Boiler & 0.6015 & - & 0.4903 & -0.05475 & 0.5495 & - & 0.324020 & - \\
\hline 7 & Economizer & 0.2120 & - & 0.3392 & -0.36030 & 0.3049 & - & 0.141110 & - \\
\hline 8 & Pump & 0.0033 & - & 0.0005 & - & 0.0016 & - & 0.001867 & - \\
\hline 9 & Generator & - & - & - & - & - & - & 0.000058 & - \\
\hline
\end{tabular}

\subsection{Combined Cycle Power Plant}

Table 4 represents the residue cost distribution ratios used by Options 1 and 2 [1], Option 4 [41] and Option 5 [42]. The improved methodology applied herein uses the ratios shown in Table 5, which are the same as Option 1. Option 3, H\&S Model [43], [44], allocates residues systematically and automatically through its productive structure definition and does not need to define these ratios to be used.

As already noted in [1], [42] there are values greater than one (for the combustor) and lesser than zero (equipment 5,6 and 7) in Option 2-Table 4. It is important to recall that the value of residue cost distribution ratios should be between 0 and 1 , by reason of it represents the fraction of the total cost of a waste that is allocated to a given component.

One may note that Options 1 and 4, in Table 4, present similar behavior, charging the same equipment with the same kind of residue: the exhaust gases for combustor and compressor and the condenser residual heat for superheater, boiler, economizer and pump. Also, both present only a slight difference in $\psi_{j r}$ values. In this case study, a combined cycle, Options 1 and 4 do not penalize the equipment of the gas cycle with the condenser residual heat, although some components of this cycle may contribute to the formation of waste and its cost. In addition, both methods do not allocate the waste cost of exhaust gases to the gas turbine, it only charges the compressor and the combustion chamber, although they are all thermodynamic coupled.
Option 5, which was based on the same mathematical structure as Option 1, proposes an improved definition of waste cost distribution ratios. The biggest difference between them is in the allocation of exhaust gases also to the gas turbine, in addition to combustion and compressor, and residual heat for gas cycle equipment, in addition to those already penalized by Option 1 .

The H\&S Model does not need to define $\psi_{j r}$ values since this methodology have already been proposed taking into account the treatment of waste and dissipative component. It is carried out automatically through the definition of its productive structure and is an inherent feature of this methodology. One may note from Figure 3 that both kinds of residue are distributed to both cycles (steam and gas) through the superheater, boiler and economizer, which are the interface between them. The condenser residual heat (flow S11:12) is allocated for the steam cycle (equipment 4-8) through the bifurcation BS2, and for the gas cycle (equipment 1-3) through the bifurcation BS1. Similarly, the exhaust gases (flow S10:1) are also distributed for both cycles: through the bifurcation BS1 to the gas cycle equipment and through the junctionbifurcation $\mathrm{JH} 2-\mathrm{BH} 2$, which is linked to the interface between cycles, to the steam cycle equipment. Additionally, a share (flow H16:11) of this residue (gases) distributed to the steam cycle can be redistributed to other equipment, such as the pump (number 8 ) through its consumed power.

Table 5 shows how the $\psi_{j r}$ used in the improved methodology of this work are determined to be applied in the comprehensive diagram in Figure 4. 
It is noted through Tables 4 and 5 that in all the compared methodologies the combustor is the most penalized device in the gas cycle and the boiler in the steam cycle, i.e., these are the equipment that most contribute to the waste generation in this plant. This is due to the irreversibilities generated in the combustion process and the heat exchanges.

Figure 11 shows the exergetic unit cost of the output flows of each equipment obtained by the different methodologies applied in the combined cycle. The methodology used here is identified as 'Comprehensive' in the figure subtitle owing to the kind of diagram used. These unit costs were obtained by solving the set of Eq. (2) by considering each of the thermoeconomic diagrams shown in Figures 2-4.

As expected, all the methodologies determine the same unit cost for the output flow in equipment 9, the generator, because its product is the only final product of the system.

Options 1, 4 and 5 present similar values in most cases since they use total exergy flows to define the productive diagram and some similarities to obtain the $\psi_{j r}$. Option 2 obtains slightly different values, e.g., equipment 4, 7, 10 and 11 , since it may lead to some inconsistencies in open cycles. Option 3 also presents slightly different values (equipment 4, 7 and 11, for instance) because of the criterion used for residue cost allocation in which is not necessary to define the $\psi_{j r}$ to reinternalize the residue cost.

The methodology herein applied, using the comprehensive diagram, presents approximate results when compared with the main methodologies available in the literature indicating an agreement among them. However, the biggest difference of this alternative approach, when compared with Options 1, 2, 4 and 5 (literature), is that the equipment product/fuel ratio does not change, since it does not allocate waste cost directly in the productive unit that generated it. If the residue cost is allocated directly in the productive unit that has generated it, this reallocated cost could be interpreted as a "fuel" for this equipment and consequently modify the fuel/product ratio, the unit exergy consumption, that represents the equipment performance index used in thermoeconomic diagnosis method called "Fuel Impact Formula" [50], [51]. It should be indeed mentioned that changing product/fuel ratio could indicate a malfunction where it does not exist, generate an inappropriate interpretation and damaging the diagnosis analysis. When using the comprehensive diagram, the residues costs are allocated in the internal loop of physical flows (Figure 4). Thereby, the equipment performance index does not change and, thus, it is useful in avoiding misconceptions regarding the power/fuel ratio.

In addition, this methodology can reduce the possible complexity involved in the exergy disaggregation and the arbitrariness linked to the use of junctions-bifurcations for subsystem interconnections.

In Option 3, regardless of whether it is used with a productive or comprehensive diagram, there is no possibility of inconsistencies related to the diagnosis, since the cost of the waste is not re-internalized in this way, but through the productive diagram as an inherent feature of the model.

Table 5. Residue cost distribution ratios - Comprehensive diagram, E Model.

\begin{tabular}{clcccc}
\hline \multirow{2}{*}{$N^{\circ}$} & \multirow{2}{*}{ Device } & \multicolumn{2}{c}{ Heat } & \multicolumn{2}{c}{ Gases } \\
\cline { 2 - 6 } & & Equation & $\boldsymbol{\psi}_{\text {jr }}[\%]$ & Equation & $\boldsymbol{\psi}_{\text {jr }}[\%]$ \\
\hline 1 & Combustor & - & - & $\mathrm{E}_{3: 2} /\left(\mathrm{E}_{3: 2}+\mathrm{E}_{2: 1}\right)$ & 0.6069 \\
2 & Compressor & - & - & $\mathrm{E}_{2: 1} /\left(\mathrm{E}_{3: 2}+\mathrm{E}_{2: 1}\right)$ & 0.3931 \\
3 & Gas Turbine & - & - & - & - \\
4 & LP Turbine & - & 0.1832 & - & - \\
5 & Superheater & $\mathrm{E}_{16: 15} /\left(\mathrm{E}_{16: 15}+\mathrm{E}_{15: 14}+\mathrm{E}_{14: 13}+\mathrm{E}_{13: 12}\right)$ & - & - \\
6 & Boiler & $\mathrm{E}_{15: 14} /\left(\mathrm{E}_{16: 15}+\mathrm{E}_{15: 14}+\mathrm{E}_{14: 13}+\mathrm{E}_{13: 12}\right)$ & 0.6015 & - \\
7 & Economizer & $\mathrm{E}_{14: 13} /\left(\mathrm{E}_{16: 15}+\mathrm{E}_{15: 14}+\mathrm{E}_{14: 13}+\mathrm{E}_{13: 12}\right)$ & 0.2120 & - & - \\
8 & Pump & $\mathrm{E}_{13: 12} /\left(\mathrm{E}_{16: 15}+\mathrm{E}_{15: 14}+\mathrm{E}_{14: 13}+\mathrm{E}_{13: 12}\right)$ & 0.0033 & - & - \\
9 & Generator & - & - & - & - \\
\hline
\end{tabular}

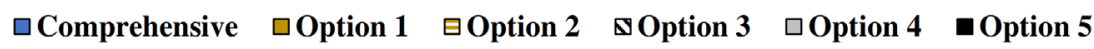

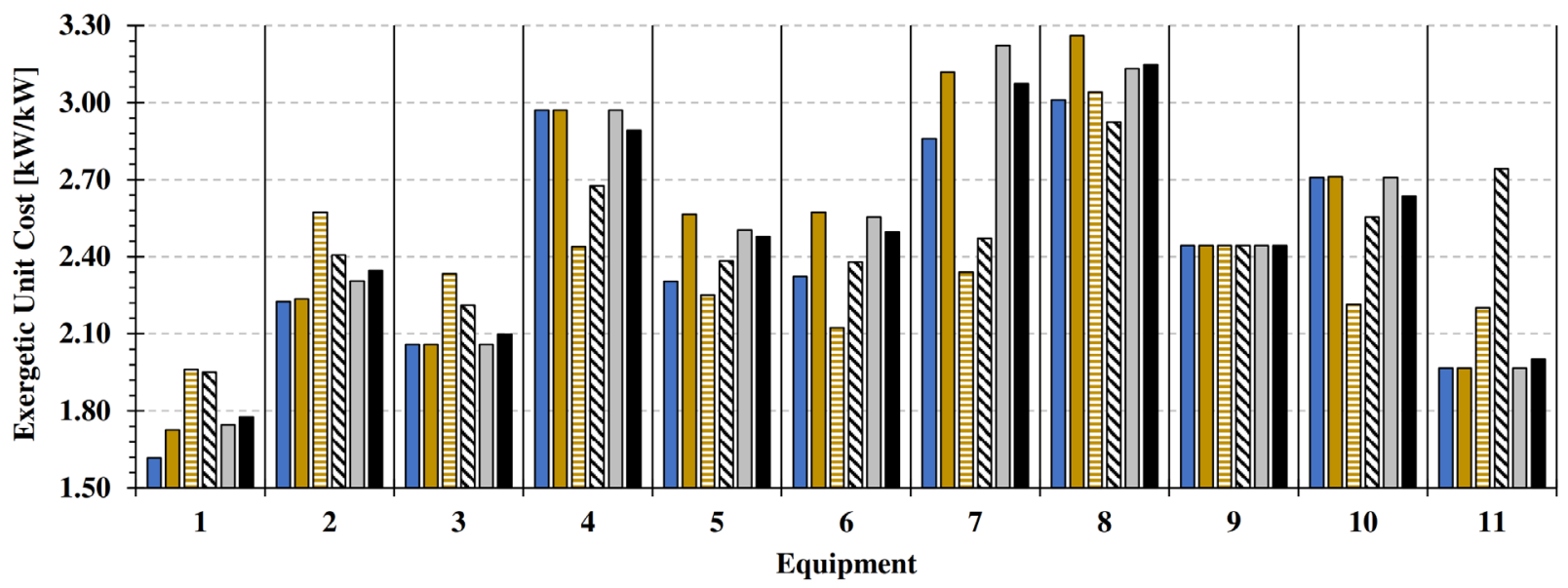

Figure 11. Exergetic unit cost of the output flow of each equipment in the combined cycle. 
Table 6. Residue cost distribution ratios - comprehensive diagram.

\begin{tabular}{|c|c|c|c|c|}
\hline \multirow{2}{*}{ Equipment } & \multicolumn{2}{|c|}{ Model E } & \multicolumn{2}{|c|}{ Model $\mathbf{E}^{\mathrm{T}} \boldsymbol{\&} \mathbf{E}^{\mathrm{M}}$} \\
\hline & Equation & $(\%)$ & Equation & $(\%)$ \\
\hline Compressor - AC & $\mathrm{E}_{2: 1} /\left(\mathrm{E}_{2: 1}+\mathrm{E}_{3: 2}+\mathrm{E}_{4: 3}\right)$ & 0.2636 & $\mathrm{E}_{2: 1}^{\mathrm{T}} /\left(\mathrm{E}_{2: 1}^{\mathrm{T}}+\mathrm{E}_{3: 2}^{\mathrm{T}}+\mathrm{E}_{4: 3}^{\mathrm{T}}\right)$ & 0.1077 \\
\hline Regenerator $-\mathrm{R}$ & $\mathrm{E}_{3: 2} /\left(\mathrm{E}_{2: 1}+\mathrm{E}_{3: 2}+\mathrm{E}_{4: 3}\right)$ & 0.1796 & $\mathrm{E}_{3: 2}^{\mathrm{T}} /\left(\mathrm{E}_{2: 1}^{\mathrm{T}}+\mathrm{E}_{3: 2}^{\mathrm{T}}+\mathrm{E}_{4: 3}^{\mathrm{T}}\right)$ & 0.2257 \\
\hline Combustion chamber - CC & $\mathrm{E}_{4: 3} /\left(\mathrm{E}_{2: 1}+\mathrm{E}_{3: 2}+\mathrm{E}_{4: 3}\right)$ & 0.5568 & $\mathrm{E}_{4: 3}^{\mathrm{T}} /\left(\mathrm{E}_{2: 1}^{\mathrm{T}}+\mathrm{E}_{3: 2}^{\mathrm{T}}+\mathrm{E}_{4: 3}^{\mathrm{T}}\right)$ & 0.6666 \\
\hline Gas Turbine - GT & - & - & - & - \\
\hline Recovery boiler - CR & - & - & - & - \\
\hline
\end{tabular}

Figure 12 shows the straight line with the results of the thermoeconomic models for the combined cycle and compares the exergetic unit costs obtained for the products of the two turbines (gas and steam), using the different methodologies. Similar results are obtained by the improved methodology (Comprehensive) and Options 1 and 4 , because all of them define quite similar values for the residues cost distribution ratios. The most contrasting value is obtained by Option 2, probably due to the $\psi_{j r}$ used, as already mentioned, greater than one and lesser than zero for some equipment and also because it is not indicated for open cycles. Options 3 and 5 defines intermediate values in function of the different diagrams (with disaggregated exergy flows) and criteria used for residue cost allocation.

Despite the difference obtained by Option 2, the other approaches present close results confirming their ability to treat waste even using different criteria.

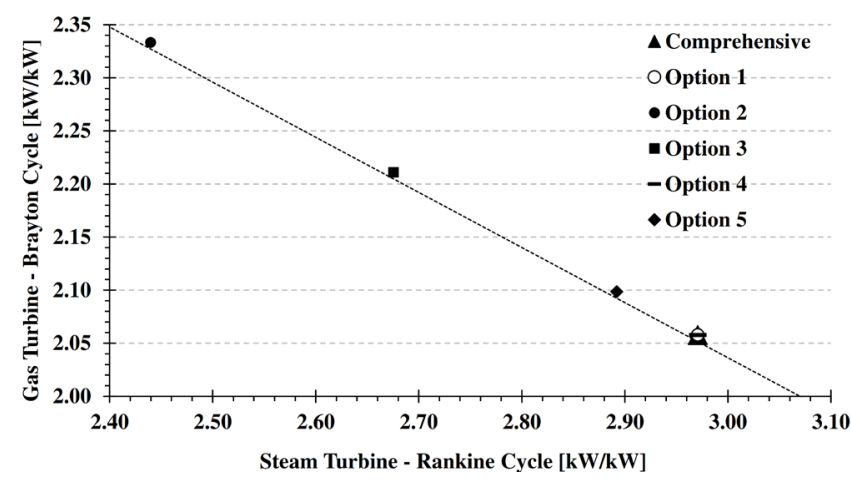

Figure 12. Exergetic unit cost of the two mechanical power flows produced in the combined cycle.

\subsection{Regenerative gas turbine cogeneration system}

Table 6 shows how the $\psi_{j r}$ used in the methodology of this work is determined to be applied in the comprehensive diagrams (Models $\mathrm{E}$ and $\mathrm{E}^{\mathrm{T}} \& \mathrm{E}^{\mathrm{M}}$ ) of the CGAM system in Figures 9 and 10. It is worth emphasizing that in the Model $\mathrm{E}^{\mathrm{T}} \& \mathrm{E}^{\mathrm{M}}$ the residues are represented only by exergy thermal component and thereby, the $\psi_{j r}$ are obtained through this kind of flows only.

It is noticed in Table 6 that in both cases the combustion chamber (CC) is the biggest responsible for the residue generation, however it is not the only one. The other methodologies compared in this case study do not need to define these proportions. As already explained, all of them (EFA, TFA, H\&S and E/SPECO) allocate the waste cost using different criteria (see section 2).

Figure 13 compares the exergetic unit cost of the final products obtained by the comprehensive diagrams (Models $\mathrm{E}$ and $\mathrm{E}^{\mathrm{T}} \& \mathrm{E}^{\mathrm{M}}$ ) with EFA, TFA, SPECO/Model E, and also with the H\&S Model for the CGAM system. All applied methods provide coherent results of unit costs belonging to the straight line with the results which is specifically for the heat to power ratio and the overall exergetic efficiency considered in this cogeneration plant.

Additionally to using the by-product criterion to define the auxiliary equations, the EFA, in which the residues are reallocated through the environment, uses the negentropy term in addition to exergy components and have already been criticized [43], [44], [56], as this term is already included in the total exergy term. Moreover, in cost allocation analysis, it was demonstrated that the negentropy flow (when used together with exergy flows) overloads the unit cost of power in detriment of the unit cost of heat in cogeneration plants [3], [43], [44], [56].

The exergetic unit cost of the final products obtained by E Model, which uses productive diagram and allocates the residue implicitly to the final products $\left(\mathrm{P}_{\mathrm{N}}\right.$ and $\left.\mathrm{Q}_{\mathrm{U}}\right)$ in proportion to the exergetic inputs of the GT and the RB, respectively, are similar to those obtained by the proposal of this work (Comprehensive diagram - E Model) in which the residues costs are reallocated in the $\mathrm{AC}, \mathrm{R}$ and $\mathrm{CC}$ proportionally the contribution of each one. In both cases, total exergy flows are used for diagram definition. The difference between them is in the kind of diagram used and how the residues costs are reallocated. Figure 13 subtitle shows "E/SPECO Model" since as mentioned earlier, these methodologies presented the same results for the unit costs compared.

The exergetic unit cost of power and heat obtained by TFA is approximated to that obtained by the proposal of this work, Model $\mathrm{E}^{\mathrm{T}} \& \mathrm{E}^{\mathrm{M}}$ - Comprehensive since both use flows of disaggregated exergy in their thermal and mechanical components for diagram definition. Besides, both of them treat the waste through the thermal component only. Whereas in the TFA it is allocated implicitly to final products $\left(\mathrm{P}_{\mathrm{N}}\right.$ and $\left.\mathrm{Q}_{\mathrm{U}}\right)$ proportionally to the inputs of the $\mathrm{GT}$ and the $\mathrm{RB}$, in the comprehensive diagram the residues costs are reallocated where it was produced $(\mathrm{AC}, \mathrm{R}$ and $\mathrm{CC})$ and proportionally to this production.

Despite the similar results obtained by "E/SPECO Model" and "Model E - comprehensive" and also by "TFA" and "Model $\mathrm{E}^{\mathrm{T}} \& \mathrm{E}^{\mathrm{M}}$ - comprehensive", the methodology presented in this work has the advantage of not altering an important equipment performance index $(\mathrm{P} / \mathrm{F})$ used in thermoeconomic diagnosis.

The H\&S Model, which treats the residues in the environment defined in its productive structure, obtains intermediate values for the ordered pair of heat and power unit costs. Nevertheless, in contrast to the EFA, which also uses the environment and the negentropy term, it does not present inconsistent values for unit cost or efficiencies and follows a systematic procedure that is able to treat residues and dissipative components in thermoeconomic analysis. One needs to highlight that the H\&S Model approached negentropy with a different perspective from that used in EFA: as the entropic component to be used together with enthalpy, both considered as components of exergy [80]. 


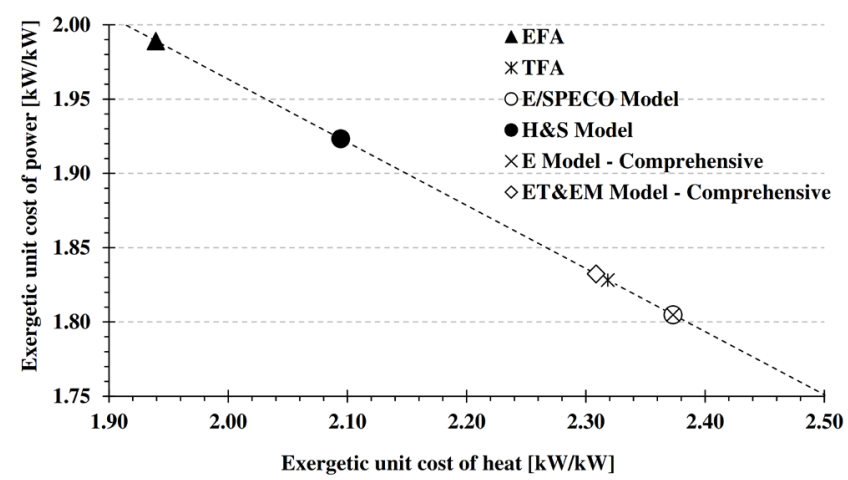

Figure 13. Exergetic unit cost of the final products for the CGAM system.

The results showed in Figure 13 were obtained by the comprehensive diagrams ( $\mathrm{E}$ and $\mathrm{E}^{\mathrm{T}} \& \mathrm{E}^{\mathrm{M}}$ Models) considering the reallocation of the residues costs, as explained in subsection 4.2.2. However, as some works [2], [4] indicate that the residue should be reallocated only in the combustion chamber, Tables 7 and 8 compare how the exergetic unit costs would be considering that the costs of waste were reallocated only to the combustion chamber (component) or proportionally divided (see Table 6) among combustion chamber, compressor and regenerator (internal loop of physical flow) according to its responsibilities as proposed in this paper.

Table 7. Exergetic unit cost $[\mathrm{kW} / \mathrm{kW}]$ for the CGAM system - Comprehensive diagram E Model.

\begin{tabular}{ccc}
\hline Flow & \multicolumn{2}{c}{ Residue Allocation } \\
\cline { 2 - 3 } & $\begin{array}{c}\text { Combustion } \\
\text { chamber } \\
\text { (component) }\end{array}$ & $\begin{array}{c}\text { Combustion chamber, } \\
\text { compressor and regenerator } \\
\text { (internal loop - Figure 9) }\end{array}$ \\
\hline $\mathrm{E}_{2: 1}$ & 1.9608 & 1.9608 \\
$\mathrm{E}_{3: 2}$ & 1.9397 & 1.9397 \\
$\mathrm{E}_{4: 3}$ & 1.4612 & 1.4612 \\
$\mathbf{E}_{\mathbf{2}}$ & $\mathbf{2 . 1 5 6 8}$ & $\mathbf{2 . 0 1 2 4}$ \\
$\mathbf{E}_{\mathbf{3}}$ & $\mathbf{2 . 0 6 8 8}$ & $\mathbf{2 . 0 0 3 9}$ \\
$\mathrm{E}_{4}=\mathrm{E}_{5}=\mathrm{E}_{6}=\mathrm{E}_{7}$ & 1.7305 & 1.7305 \\
$=\mathrm{E}_{4: 5}=\mathrm{E}_{5: 6}=\mathrm{E}_{6: 7}$ & 1.8049 & 1.8049 \\
$\mathrm{P}_{\mathrm{C}}=\mathrm{P}_{\mathrm{N}}$ & 2.3731 & 2.3731 \\
$\mathrm{Q}_{\mathrm{u}}$ &
\end{tabular}

Although it does not change the exergetic unit cost of the final products, due to the fact that the products are downstream the combustion chamber and the comprehensive diagram appropriately performs the allocation, this comparison presents variations in some internal flows $\left(E_{2}\right.$ and $\left.E_{3}\right)$ due to the different residue treatment for $\mathrm{E}$ Model - Table 7. These differences are around $6.69 \%$ and $3.14 \%$ in the flows $E_{2}$ and $E_{3}$, respectively.

For the Model $\mathrm{E}^{\mathrm{T}} \& \mathrm{E}^{\mathrm{M}}$ - Table 8 , the tendency is the same: despite it does not change the unit costs of the final products, it generates a difference in costs of internal flows, $E^{T}{ }_{2}$ and $E_{3}{ }_{3}$, due to the residue reallocating criterion. Such variation occurs in thermal components of physical exergy since in this model the residue is represented only by this thermodynamic magnitude. The differences are around $12.08 \%$ and $3.32 \%$ in the flows $\mathrm{E}^{\mathrm{T}}{ }_{2}$ and $\mathrm{E}_{3}^{\mathrm{T}}$, respectively.

When using the comprehensive diagram, both comparisons, Tables 7 and 8, showed variations in the cost values of the flows in the case studies, which is in agreement that the equipment that contributed to the formation of the residues must be penalized. Beyond these differences, the proposal of this work differs from the others because it does not reallocate the residue directly in the productive unit, but rather on the internal loop of physical exergy. Hence, the reallocated residue cannot be interpreted as a "fuel" in the equipment and the product/fuel ratio of the same is not changed. It is worth remembering that this reason is relevant in thermoeconomic diagnosis methodologies.

Table 8. Exergetic unit cost [kW/kW] for the CGAM system - Comprehensive diagram Model $E^{T} \& E^{M}$.

\begin{tabular}{|c|c|c|}
\hline \multirow[b]{2}{*}{ Flow } & \multicolumn{2}{|c|}{ Residue Allocation } \\
\hline & $\begin{array}{l}\text { Combustion } \\
\text { chamber } \\
\text { (component) }\end{array}$ & $\begin{array}{l}\text { Combustion chamber, } \\
\text { compressor and } \\
\text { regenerator (internal } \\
\text { loop - Figure 10) } \\
\end{array}$ \\
\hline $\begin{array}{l}\mathrm{E}_{2: 1}^{\mathrm{M}_{2}}=\mathrm{E}^{\mathrm{M}_{2: 3}}=\mathrm{E}_{3: 4}^{\mathrm{M}_{3: 4}}=\mathrm{E}^{\mathrm{M}}{ }_{4: 5} \\
=\mathrm{E}^{\mathrm{M}}{ }_{5: 6}=\mathrm{E}^{\mathrm{M}}{ }_{6: 7}=\mathrm{E}^{\mathrm{M}_{2}}=\mathrm{E}^{\mathrm{M}_{3}} \\
=\mathrm{E}^{\mathrm{M}_{4}}=\mathrm{E}^{\mathrm{M}}{ }_{5}=\mathrm{E}^{\mathrm{M}}{ }_{6}=\mathrm{E}^{\mathrm{M}}{ }_{7}\end{array}$ & 1.9906 & 1.9906 \\
\hline $\mathrm{E}_{2: 1}^{\mathrm{T}}$ & 1.9906 & 1.9906 \\
\hline $\mathrm{E}_{3: 2}^{\mathrm{T}}$ & 1.8852 & 1.8852 \\
\hline $\mathrm{E}_{4: 3}^{\mathrm{T}}$ & 1.5039 & 1.5039 \\
\hline $\begin{array}{l}\mathrm{E}^{\mathrm{T}}{ }_{4: 5}=\mathrm{E}^{\mathrm{T}}{ }_{5: 6}=\mathrm{E}^{\mathrm{T}}{ }_{6: 7}=\mathrm{E}^{\mathrm{T}}{ }_{4} \\
=\mathrm{E}_{5}^{\mathrm{T}}=\mathrm{E}_{6}^{\mathrm{T}}=\mathrm{E}_{7}^{\mathrm{T}}=\mathrm{E}_{7: 1}^{\mathrm{T}}\end{array}$ & 1.6759 & 1.6759 \\
\hline $\mathbf{E}_{2}^{\mathrm{T}}$ & 2.3021 & 2.0241 \\
\hline $\mathbf{E}^{\mathrm{T}}{ }_{3}$ & 2.0198 & 1.9528 \\
\hline $\mathrm{P}_{\mathrm{C}}=\mathrm{P}_{\mathrm{N}}$ & 1.8323 & 1.8323 \\
\hline $\mathrm{Q}_{\mathrm{U}}$ & 2.3086 & 2.3086 \\
\hline
\end{tabular}

\section{Conclusions and closure}

A bibliographic review concerning the treatment of waste and dissipative equipment in thermoeconomics was carried out in order to identify and enumerate the main conventional methodologies used in this field. An improved approach that uses the comprehensive diagram for residues cost allocation was explained and applied in two case studies, which were chosen because they have already been explored by the methodologies compared here. In both cases, the combined cycle and the CGAM system, there are residues in the system that need to be considered in the analysis. Results were compared with the different methodologies applied in the last years in the same cycles and that are available in the literature.

The improved methodology herein applied agrees that the cost of the exergy contained in the residues and the costs of the resources employed in its treatment or evacuation must be divided among the productive units that have generated it proportionally to its responsibility for such magnitude. The update of this method is in the way the waste cost is relocated: in the internal loop instead of directly in the productive unit that generated the waste.

For the combined cycle, when compared with the main available methodologies, the proposal of this work provides coherent results from the point of view of proportionally penalizing the equipment in which the waste was generated. The exergetic unit cost values for both internal flows and products of the two turbines (gas and steam) are consistent and approximated to those obtained by other compared methodologies. The small differences are due to the reallocation waste criteria adopted: while Options 1, 2, 4 and 5 and the proposal of this work need to define the residue cost distribution ratio to reinternalize the residue 
cost, in Option 3 it is an inherent feature of the methodology which allocates waste cost through its productive structure.

For the regenerative gas cycle, comprehensive diagram modeling was done with $\mathrm{E}$ Model and Model $\mathrm{E}^{\mathrm{T}} \& \mathrm{E}^{\mathrm{M}}$ and both provided coherent exergetic unit costs belonging to the straight line with the results. In addition, the proposal of this paper is in agreement with known methodologies that allocate residues only in the combustion chamber when the comparison was carried out allocating the residue only to the combustion chamber or sharing its cost to combustion chamber, regenerator and air compressor. In both cases, the exergetic unit costs of the final products were the same, with only slight differences in the internal flow costs related to equipment that produces waste.

Regarding residue cost allocation criteria, the methodologies compared in this paper can be classified as follow: most of them (Options 1-2, 4-5 and the proposal of this work) need to define the $\psi_{j r}$ for waste cost reallocation; the E Model/SPECO and the TFA allocate implicitly proportionally to the exergy consumption in the productive unit that produces the final products; the EFA uses negentropy flow consumption along with the thermal exergy component flow and the H\&S Model allocates automatically through the definition of its productive structure as an inherent feature of this model.

Despite the differences in the criteria for waste costs allocation among the different methodologies compared in this work, results show that most of them present rational results for exergetic unit costs and residue cost allocation with some similarities. However, the major contribution of the proposal of this work is related to its future application in thermoeconomic diagnosis analysis. If this analysis is performed with the well-known "Fuel Impact Formula" method in a plant with residues, the allocation of residue cost directly in the productive unit that has generated it may lead to inappropriate interpretations, since the residues are not resources. Once using the comprehensive diagram and allocating the residues costs in the internal loop of physical flows, the equipment performance index used in the diagnosis method above mentioned does not change and allow a rational analysis of malfunctions and dysfunctions present in the system.

\section{Acknowledgments}

The authors would like to thank FAPES, UFES, IFES, CAPES and TEVISA by financial support.

\section{Nomenclature}

$\begin{array}{lll}\mathrm{c} & \text { Monetary unit cost } & {[\$ / \mathrm{kWh}]} \\ \mathrm{CH} & \text { Chemical exergy } & {[\mathrm{kW}]} \\ \mathrm{E} & \text { Exergy flow } & {[\mathrm{kW}]} \\ \mathrm{FP} & \text { Table Fuel-Product } & \\ \mathrm{H} & \text { Enthalpy flow } & {[\mathrm{kW}]} \\ k & \text { Exergetic unit cost } & {[\mathrm{kW} / \mathrm{kW}]} \\ \mathrm{m} & \text { Mass flow } & {[\mathrm{kg} / \mathrm{s}]} \\ \mathrm{P} & \text { Power } & {[\mathrm{kW}]} \\ \mathrm{Q} & \text { Heat (exergy) } & {[\mathrm{kW}]} \\ \mathrm{S} & \text { Entropy flow } & {[\mathrm{kW}]} \\ \mathrm{Y} & \text { Generic thermodynamic magnitude } & {[\mathrm{kW}]} \\ \mathrm{Z} & \text { Hourly equipment cost } & {[\$ / \mathrm{h}]}\end{array}$

\section{Greek symbols}

$\psi_{j r} \quad$ Residue cost distribution ratio

$\begin{array}{ll}\text { Subscripts and superscripts } \\ \mathrm{F} & \text { Fuel } \\ \mathrm{H} & \text { Enthalpic } \\ \mathrm{i}, \mathrm{j} & \text { Indexes for productive components } \\ \text { in } & \text { Inlet } \\ \mathrm{M} & \text { Mechanical } \\ \mathrm{N} & \text { Net } \\ \text { out } & \text { Outlet } \\ \mathrm{r} & \text { Index for dissipative components } \\ \mathrm{S} & \text { Entropic } \\ \mathrm{T} & \text { Thermal } \\ \mathrm{U} & \text { Useful }\end{array}$

\section{References:}

[1] C. Torres, A. Valero, V. Rangel, and A. Zaleta, "On the cost formation process of the residues," Energy, vol. 33, no. 2, pp. 144-152, Feb. 2008, doi: 10.1016/j.energy.2007.06.007.

[2] C. Torres and A. Valero, "Curso de Doctorado Termoeconomía, Dpto. Ingenieria Mecánica." Universidad de Zaragoza, 2000.

[3] S. A. A. G. Cerqueira, "Metodologias de Análise Termoeconômica de Sistemas [in Portuguese]," Universidade Estadual de Campinas, Campinas, Brazil, 1999.

[4] A. Lazzaretto and G. Tsatsaronis, "SPECO: A systematic and general methodology for calculating efficiencies and costs in thermal systems," Energy, vol. 31, no. 8-9, pp. 1257-1289, Jul. 2006, doi: 10.1016/j.energy.2005.03.011.

[5] A. Pablo Arena and R. Borchiellini, "Application of different productive structures for thermoeconomic diagnosis of a combined cycle power plant," International Journal of Thermal Sciences, vol. 38, no. 7, pp. 601-612, Jul. 1999, doi: 10.1016/S00353159(99)80040-3.

[6] İ. Dincer and M. A. Rosen, Exergy: Energy, Environment, and Sustainable Development, 1st ed. Elsevier Science, 2007.

[7] M. A. Rosen and I. Dincer, "Exergy as the confluence of energy, environment and sustainable development," Exergy, An International Journal, vol. 1, no. 1, pp. 313, Jan. 2001, doi: 10.1016/S1164-0235(01)00004-8.

[8] M. A. Rosen and I. Dincer, "On Exergy and Environmental Impact," International Journal of Energy Research, vol. 21, no. 7, pp. 643-654, Jun. 1997, doi: 10.1002/(SICI)1099114X(19970610)21:7<643::AID-ER284>3.0.CO;2-I.

[9] H. Holmberg, M. Tuomaala, T. Haikonen, and P. Ahtila, "Allocation of fuel costs and CO2-emissions to heat and power in an industrial CHP plant: Case integrated pulp and paper mill," Applied Energy, vol. 93, pp. 614-623, May 2012, doi: 10.1016/j.apenergy.2011.11.040.

[10] J. A. M. Silva, D. Flórez-Orrego, and S. Oliveira, “An exergy based approach to determine production cost and $\mathrm{CO} 2$ allocation for petroleum derived fuels," Energy, vol. 67, pp. 490-495, Apr. 2014, doi: 10.1016/j.energy.2014.02.022.

[11] D. Flórez-Orrego, J. A. M. Silva, and S. de Oliveira Jr., "Renewable and non-renewable exergy cost and specific $\mathrm{CO} 2$ emission of electricity generation: The Brazilian case," Energy Conversion and Management, vol. 85, pp. 619-629, Sep. 2014, doi: 
10.1016/j.enconman.2014.04.058.

[12] D. Flórez-Orrego, J. A. M. da Silva, H. Velásquez, and S. de Oliveira, "Renewable and non-renewable exergy costs and $\mathrm{CO} 2$ emissions in the production of fuels for Brazilian transportation sector," Energy, vol. 88, pp. 18-36, Aug. 2015, doi: 10.1016/j.energy.2015.05.031.

[13] P. S. Ortiz, D. Flórez-Orrego, S. de Oliveira, R. M. Filho, P. Osseweijer, and J. Posada, "Unit exergy cost and specific $\mathrm{CO} 2$ emissions of the electricity generation in the Netherlands," Energy, p. 118279, Jul. 2020, doi: 10.1016/j.energy.2020.118279.

[14] R. G. Santos, P. R. Faria, J. J. C. S. Santos, and J. A. M. da Silva, "Thermoeconomic modeling for $\mathrm{CO} 2$ allocation in steam and gas turbine cogeneration systems," in ECOS 2015 proceedings of the 28th International Conference on Efficiency, Cost, Optimization, Simulation and Environmental Impact of Energy Systems, 2015.

[15] R. G. Santos, P. R. Faria, J. J. C. S. Santos, J. A. M. Silva, and D. Flórez-Orrego, "Thermoeconomic modeling for $\mathrm{CO} 2$ allocation in steam and gas turbine cogeneration systems," Energy, vol. 117, pp. 590603, Jan. 2016, doi: 10.1016/j.energy.2016.04.019.

[16] R. G. dos Santos, J. J. C. S. Santos, and J. A. M. da Silva, "Application of Thermoeconomics for $\mathrm{CO} 2$ Allocation for Net Power and Useful Heat in a Gas Turbine Cogeneration System," Applied Mechanics and Materials, vol. 830, pp. 95-108, Mar. 2016, doi: 10.4028/www.scientific.net/AMM.830.95.

[17] J. A. M. Silva and S. Oliveira, "An exergy-based approach to determine production cost and $\mathrm{CO} 2$ allocation in refineries," Energy, vol. 67, pp. 607-616, Apr. 2014, doi: 10.1016/j.energy.2014.01.036.

[18] D. Flórez-Orrego and S. de Oliveira Junior, "On the efficiency, exergy costs and CO 2 emission cost allocation for an integrated syngas and ammonia production plant," Energy, vol. 117, pp. 341-360, Dec. 2016, doi: 10.1016/j.energy.2016.05.096.

[19] J. A. M. da Silva and S. de Oliveira Junior, "Unit exergy cost and $\mathrm{CO} 2$ emissions of offshore petroleum production," Energy, vol. 147, pp. 757-766, Mar. 2018, doi: 10.1016/j.energy.2018.01.100.

[20] J. Gao, Q. Zhang, X. Wang, D. Song, W. Liu, and W. Liu, "Exergy and exergoeconomic analyses with modeling for $\mathrm{CO} 2$ allocation of coal-fired CHP plants," Energy, vol. 152, pp. 562-575, Jun. 2018, doi: 10.1016/j.energy.2018.03.171.

[21] M. Carvalho, E. S. da Silva, S. L. F. Andersen, and R. Abrahão, "Life cycle assessment of the transesterification double step process for biodiesel production from refined soybean oil in Brazil," Environmental Science and Pollution Research, vol. 23, no. 11, pp. 11025-11033, Jun. 2016, doi: 10.1007/s11356-016-6295-z.

[22] J. A. M. da Silva, J. J. C. S. Santos, M. Carvalho, and $\mathrm{S}$. de Oliveira, "On the thermoeconomic and LCA methods for waste and fuel allocation in multiproduct systems," Energy, vol. 127, pp. 775-785, May 2017, doi: 10.1016/j.energy.2017.03.147.

[23] A. F. C. Fortes, M. Carvalho, and J. A. M. da Silva, "Environmental impact and cost allocations for a dual product heat pump," Energy Conversion and Management, vol. 173, pp. 763-772, Oct. 2018, doi: 10.1016/j.enconman.2018.07.100.
[24] M. . Rocha, E. E. S. Lora, O. J. Venturini, J. J. C. S. Santos, and A. . Moura, "Use of the life cycle assessment (LCA) for comparison of the environmental performance of four alternatives for the treatment and disposal of bioethanol stillage," International Sugar Journal, vol. 112, pp. 611-622, 2010.

[25] M. Carvalho et al., "Alocação em sistemas energéticos multiproduto: revisão e proposta de métodos," LALCA: Revista Latino-Americana em Avaliação do Ciclo de Vida, vol. 4, p. e44660, Jul. 2020, doi: 10.18225/lalca.v4i0.4660.

[26] E. J. C. Cavalcanti, M. Carvalho, and J. L. B. Azevedo, "Exergoenvironmental results of a eucalyptus biomass-fired power plant," Energy, vol. 189, p. 116188, Dec. 2019, doi: 10.1016/j.energy.2019.116188.

[27] E. J. C. Cavalcanti, M. Carvalho, and D. R. S. da Silva, "Energy, exergy and exergoenvironmental analyses of a sugarcane bagasse power cogeneration system," Energy Conversion and Management, vol. 222, p. 113232, Oct. 2020, doi: 10.1016/j.enconman.2020.113232.

[28] H. Cho, P. J. Mago, R. Luck, and L. M. Chamra, "Evaluation of CCHP systems performance based on operational cost, primary energy consumption, and carbon dioxide emission by utilizing an optimal operation scheme," Applied Energy, vol. 86, no. 12, pp. 2540-2549, Dec. 2009, doi: 10.1016/j.apenergy.2009.04.012.

[29] J.-J. Wang, Y.-Y. Jing, and C.-F. Zhang, "Optimization of capacity and operation for CCHP system by genetic algorithm," Applied Energy, vol. 87, no. 4, pp. 1325-1335, Apr. 2010, doi: 10.1016/j.apenergy.2009.08.005.

[30] S. Bracco, G. Dentici, and S. Siri, "Economic and environmental optimization model for the design and the operation of a combined heat and power distributed generation system in an urban area," Energy, vol. 55, pp. 1014-1024, Jun. 2013, doi: 10.1016/j.energy.2013.04.004.

[31] E. A. Pina, M. A. Lozano, and L. M. Serra, “A multiperiod multiobjective framework for the synthesis of trigeneration systems in tertiary sector buildings," International Journal of Energy Research, vol. 44, no. 2, pp. 1140-1166, Feb. 2020, doi: 10.1002/er.5006.

[32] E. S. Pinto, L. M. Serra, and A. Lázaro, "Evaluation of methods to select representative days for the optimization of polygeneration systems," Renewable Energy, vol. 151, pp. 488-502, May 2020, doi: 10.1016/j.renene.2019.11.048.

[33] A. Valero et al., "CGAM problem: Definition and conventional solution," Energy, vol. 19, no. 3, pp. 279-286, Jan. 1994, doi: 10.1016/03605442(94)90112-0.

[34] A. Valero, M. A. Lozano, L. Serra, and C. Torres, "Application of the exergetic cost theory to the CGAM problem," Energy, vol. 19, no. 3, pp. 365381, Feb. 1994, doi: 10.1016/0360-5442(94)90116-3.

[35] G. Tsatsaronis and J. Pisa, "Exergoeconomic evaluation and optimization of energy systems application to the CGAM problem," Energy, vol. 19, no. 3, pp. 287-321, Jan. 1994, doi: 10.1016/03605442(94)90113-9. 
[36] C. A. Frangopoulos, "Application of the thermoeconomic functional approach to the CGAM problem," Energy, vol. 19, no. 3, pp. 323-342, Jan. 1994, doi: 10.1016/0360-5442(94)90114-7.

[37] M. R. von Spakovsky, "Application of engineering functional analysis to the analysis and optimization of the CGAM problem," Energy, vol. 19, no. 3, pp. 343364, Jan. 1994, doi: 10.1016/0360-5442(94)90115-5.

[38] C. Torres, L. Serra, A. Valero, and M. A. Lozano, "The productive structure and thermoeconomic theories of system optimization," 1996.

[39] B. Erlach, "Comparison of Thermoeconomic Methodologies: Structural Theory, AVCO and LIFO, Application to a Combined Cycle," University of Zaragoza, 1998.

[40] B. Erlach, L. Serra, and A. Valero, "Structural theory as standard for thermoeconomics," Energy Conversion and Management, vol. 40, no. 15-16, pp. 1627-1649, Jan. 1999, doi: 10.1016/S01968904(99)00057-6.

[41] S. M. Seyyedi, H. Ajam, and S. Farahat, "A new criterion for the allocation of residues cost in exergoeconomic analysis of energy systems," Energy, vol. 35, no. 8, pp. 3474-3482, Aug. 2010, doi: 10.1016/j.energy.2010.04.047.

[42] A. Agudelo, A. Valero, and C. Torres, "Allocation of waste cost in thermoeconomic analysis," Energy, vol. 45, no. 1, pp. 634-643, Sep. 2012, doi: 10.1016/j.energy.2012.07.034.

[43] J. J. C. S. Santos, M. A. R. Nascimento, and E. E. S. Lora, "On The Thermoeconomic Modeling for Cost Allocation in a Dual-Purpose Power and Desalination Plant," in ECOS 2006 proceedings of the 19th International Conference on Efficiency, Cost, Optimization, Simulation and Environmental Impact of Energy Systems, 2006, pp. 441-448.

[44] J. J. C. S. Santos, M. A. R. Nascimento, E. E. S. Lora, and A. M. Martínez-Reyes, "On the Negentropy Application in Thermoeconomics: A Fictitious or an Exergy Component Flow?," International Journal of Thermodynamics, vol. 12, no. 4, pp. 163-176, 2009.

[45] M. A. Lozano and A. Valero, "Thermoeconomic analysis of gas turbine cogeneration systems," $A S M E$, NEW YORK, NY,(USA)., vol. 30, pp. 311-320, 1993.

[46] L. M. de Avellar, M. A. Barone, D. J. R. Orozco, A. B. Lourenço, J. J. C. S. Santos, and F. R. P. A. Ponce, "Comprehensive Thermoeconomic Diagram for the Thermal System Cost Assessment using Physical and Productive Internal Flows," 2018.

[47] L. M. de Avellar, M. A. Barone, D. J. R. Orozco, A. B. Lourenço, and J. J. C. S. Santos, "A Comprehensive Thermoeconomic Diagram Based on Both Subsystem Productive Purposes and Physical Connections," 2018.

[48] M. Modesto and S. A. Nebra, "Analysis of a repowering proposal to the power generation system of a steel mill plant through the exergetic cost method," Energy, vol. 31, no. 15, pp. 3261-3277, Dec. 2006, doi: 10.1016/j.energy.2006.03.032.

[49] P. R. de Faria, R. G. dos Santos, J. J. C. S. Santos, M. A. Barone, and B. M. F. Miotto, "On the Allocation of Residues Cost in Thermoeconomics using a Comprehensive Diagram," in ECOS 2020 proceedings of the 33rd International Conference on Efficiency, Cost, Optimization, Simulation and
Environmental Impact of Energy Systems, 2020, pp. 2444-2456.

[50] A. Valero, M. A. Lozano, and C. Torres, "On causality in organized energy systems, part III: theory of perturbations," 1990.

[51] A. VALERO, "On the thermoeconomic approach to the diagnosis of energy system malfunctionsPart 2. Malfunction definitions and assessment," Energy, vol. 29, no. 12-15, pp. 1889-1907, Dec. 2004, doi: 10.1016/j.energy.2004.03.008.

[52] L. M. Serra, "Optimización exergoeconómica de Sistemas Térmicos," Universidad de Zaragoza, Zaragoza, Spain, 1994.

[53] R. G. dos Santos, B. Medeiros, P. R. de Faria, J. N. Pretti, A. B. Lourenço, and J. J. C. S. Santos, "As Metodologias Termoeconômicas passados 20 anos do Problema CGAM: unificações e variantes opcionais [in portuguese]," 2014.

[54] R. G. dos Santos, “Avaliação dos Modelos Termodinâmicos e Abordagem da Alocação de CO2 em Termoeconomia [MSc. dissertation in portuguese]," Federal University of Espírito Santo (UFES), 2015.

[55] C. Torres, "Symbolic thermoeconomic analysis of energy systems," Encyclopedia of Life Support System (EOLSS), developed under the auspices of the UNESCO. In: Frangopoulos CA, editor. Exergy, energy system analysis and optimization. Oxford: EOLSS Publishers; 2004, [Online]. Available: http://www.eolss.net.

[56] J. J. C. S. Santos, M. A. R. Nascimento, E. E. S. Lora, and A. M. Martínez Reyes, "On the Productive Structure for the Residues Cost Allocation in a Gas Turbine Cogeneration Plant," in ECOS 2008 Proceedings of the 21st International Conference on Efficiency, Cost, Optimization, Simulation and Environmental Impact of Energy Systems, 2008, vol. 2, pp. 641-648.

[57] X. Luo, J. Hu, J. Zhao, B. Zhang, Y. Chen, and S. Mo, "Improved exergoeconomic analysis of a retrofitted natural gas-based cogeneration system," Energy, vol. 72, pp. 459-475, Aug. 2014, doi: 10.1016/j.energy.2014.05.068.

[58] J. J. C. S. Santos, M. A. R. do Nascimento, E. E. S. Lora, J. C. E. Palacio, and J. A. M. da Silva, "On the treatment of dissipative components and residues in thermoeconomic modeling," 2009.

[59] J. A. M. da Silva, J. J. C. S. Santos, and S. de Oliveira Jr., "The condenser product and residues allocation in thermoeconomics," 2010.

[60] S. Keshavarzian, M. V. Rocco, F. Gardumi, and E. Colombo, "Practical approaches for applying thermoeconomic analysis to energy conversion systems: Benchmarking and comparative application," Energy Conversion and Management, vol. 150, pp. 532-544, Oct. 2017, doi: 10.1016/j.enconman.2017.08.045.

[61] S. M. Seyyedi, M. Hashemi-Tilehnoee, and M. Khaleghi, "Allocating the residues cost of a typical HTGR directly integrated with steam cycle using distributed entropy method," Arab Journal of Nuclear Sciences and Applications, vol. 52, no. 1, pp. 221233, Jan. 2019, doi: 10.21608/ajnsa.2018.3875.1092.

[62] S. M. Seyyedi and A. . Dogonchi, "Two New Alternative Options for Residues Cost Distribution 
Ratio," Journal of Applied Dynamic Systems and Control, vol. Vol 1, pp. 28-36, 2018.

[63] C. Uysal and H.-Y. Kwak, "Role of Waste Cost in Thermoeconomic Analysis," Entropy, vol. 22, no. 3, p. 289, Mar. 2020, doi: 10.3390/e22030289.

[64] S.-M. Kim, S.-D. Oh, Y.-H. Kwon, and H.-Y. Kwak, "Exergoeconomic analysis of thermal systems," Energy, vol. 23, no. 5, pp. 393-406, May 1998, doi: 10.1016/S0360-5442(97)00096-0.

[65] C. Uysal and H.-Y. Kwak, "Role of Waste Cost in Theromeconomic Analysis and Impact of the Waste on Environment," in Entropy: Theory and New Insights, Vide Leaf, Hyderabad, 2020.

[66] L.-M. H. Denise, T.-G. E. Vicente, C.-H. Sergio, S.-P. Martín, L.-A. Teresa, and L.-L. Raúl, "An Irreversibility-Based Criterion to Determine the Cost Formation of Residues in a Three-Pressure-Level Combined Cycle," Entropy, vol. 22, no. 3, p. 299, Mar. 2020, doi: 10.3390/e22030299.

[67] L.-M. Helen, C.-H. Sergio, S.-P. Martín, V.-L. Javier, T.-G. E. Vicente, and L.-L. Raúl, "Residue Cost Formation of a High Bypass Turbofan Engine," Applied Sciences, vol. 10, no. 24, p. 9060, Dec. 2020, doi: 10.3390/app10249060.

[68] C. Torres and A. Valero, "The Exergy Cost Theory Revisited," Energies, vol. 14, no. 6, p. 1594, Mar. 2021, doi: 10.3390/en14061594.

[69] A. Valero, L. Serra, and J. Uche, "Fundamentals of Exergy Cost Accounting and Thermoeconomics. Part I: Theory," Journal of Energy Resources Technology, vol. 128, no. 1, p. 1, 2006, doi: 10.1115/1.2134732.

[70] M. A. Lozano and A. Valero, "Theory of the exergetic cost," Energy, vol. 18, no. 9, pp. 939-960, Sep. 1993, doi: 10.1016/0360-5442(93)90006-Y.

[71] Y. M. El-Sayed, The thermoeconomics of energy conversions. Amsterdam; Boston: Elsevier, 2003.

[72] C. A. Frangopoulos, "Thermoeconomic functional analysis: A method for Optimal Design or improvement of Complex Thermal Systems," Georgia Institute of Technology, 1983.

[73] J. J. Pacheco Ibarra, V. H. Rangel Hernández, A. Zaleta Aguilar, and A. Valero, "Hybrid Fuel Impact Reconciliation Method: An integral tool for thermoeconomic diagnosis," Energy, vol. 35, no. 5, pp. 2079-2087, May 2010, doi: 10.1016/j.energy.2010.01.026.

[74] D. J. R. Orozco, O. J. Venturini, J. C. Escobar Palacio, and O. A. del Olmo, "A new methodology of thermodynamic diagnosis, using the thermoeconomic method together with an artificial neural network (ANN): A case study of an externally fired gas turbine (EFGT)," Energy, vol. 123, pp. 20-35, Mar. 2017, doi: 10.1016/j.energy.2016.12.099.

[75] V. H. R. Hernández, "Thermoeconomic Diagnosis of Large Industrial Boilers: Microscopic Representation of the Exergy Cost Theory," Universidad de Zaragoza, 2005.

[76] C. Torres and A. Valero, "A new methodology to compute Exergy Cost Part I: The Flow-Process Table," 2018.

[77] C. Torres and A. Valero, "A new methodology to compute the Exergy Cost Part II: The generalized Irreversibility-Cost formula," 2018.

[78] Y. Wang and N. Lior, "Fuel allocation in a combined steam-injected gas turbine and thermal seawater desalination system," Desalination, vol. 214, no. 1-3, pp. 306-326, Aug. 2007, doi: 10.1016/j.desal.2007.01.001.

[79] J. Uche, "Thermoeconomic Analysis and Simulation of a Combined Power and Desalination Plant [thesis]," Universidad de Zaragoza, Zaragoza, 2000.

[80] A. B. Lourenço, S. A. Nebra, and J. J. C. S. Santos, "Another Perspective on the Physical Exergy of a Flow," 2014. 